\title{
1 Length asymmetry and heterozygosity strongly influences the 2 evolution of poly-A microsatellites at meiotic recombination 3 hotspots
}

4 Angelika Heissl ${ }^{1}$, Andrea J. Betancourt ${ }^{2}$, Philipp Hermann ${ }^{3}$, Gundula Povysil ${ }^{4,}$, Barbara Arbeithuber ${ }^{1, \&}$, 5 Andreas Futschik ${ }^{3}$, Thomas Ebner ${ }^{5}$, Irene Tiemann-Boege ${ }^{1}$

Short title: STR evolution at Recombination Hotspots

6

7

8

Author affiliations:

${ }^{1}$ Institute of Biophysics, Johannes Kepler University, 4020, Linz, Austria.

${ }^{2}$ Insitute of Integrative Biology, University of Liverpool, L69 7ZB Liverpool, UK

${ }^{3}$ Institute of Applied Statistics, Johannes Kepler University Linz, Austria

${ }^{4}$ Institute of Bioinformatics, Johannes Kepler University, 4020, Linz, Austria

${ }^{5}$ Department of Gynecology, Obstetrics and Gynecological Endocrinology, Kepler University Clinic, Campus IV, Linz, Austria

${ }^{*}$ Current address: Institute for Genomic Medicine, Columbia University, New York, USA

${ }^{\&}$ Current address: Department of Biology, Pennsylvania State University, University Park, USA

*Corresponding author: Irene Tiemann-Boege

Johannes Kepler University

Institute of Biophysics

Gruberstrasse 40-44, 4020, Linz, Austria

Tel: +4373224687620

Fax: +43 732246827620

Irene.tiemann@jku.at

Keywords: meiotic recombination, crossover, sequence evolution, short tandem repeats, microsatellites, poly-A, recombination hotspots 


\section{Abstract}

Meiotic recombination has strong, but poorly understood, effects on short tandem repeat (STR) instability. Here, we screened thousands of single recombinant products to characterize the transmission and evolution of polymorphic poly-A repeats at a human recombination hotspot. We show that length asymmetry between heterozygous poly-As plays a key role in the recombination outcome and their transmission. A difference of 10 As (9A/19A) elevates the frequency of noncrossovers, complex recombination products, and long conversion tracts. Moreover, asymmetry also influences STR transmission: the shorter allele is transmitted more frequently (deletion bias) at the asymmetric STR (9A/19A), while the longer allele is favored (insertion bias) at the site with a small

37 STR length difference $(6 \mathrm{~A} / 7 \mathrm{~A})$. Finally, potentially due to this opposing insertion/deletion driven

38 evolution, we find that poly-As are enriched at human recombination hotspots predominantly with

39 short poly-As, possibly influencing open chromatin regions that in turn can activate hotspots. 


\section{Introduction}

Repeated stretches of DNA with 1-6 bp repeat units and varying tract lengths, known as short tandem repeats (STRs) or microsatellites, comprise about 3\% of the human genome (Lander et al., 2001). STRs have attracted attention due to their association with disease (e.g. cancer and neurological disorders), [reviewed in (Boland and Goel, 2010, Shokal and Sharma, 2012, Polyzos and McMurray, 2017, Pearson et al., 2005, Richard et al., 2008)]. STR polymorphisms also play a role in gene expression variation (Gymrek et al., 2016), alternative splicing (Hui et al., 2005), chromatin packaging (Kirkpatrick et al., 1999), and nuclear organization (Pathak et al., 2013) [reviewed also in (Bagshaw, 2017)]. In spite of the functional importance of STRs, our understanding of the drivers of their evolution is far from complete [reviewed in (Ellegren, 2004, Richard et al., 2008)], with mononucleotide repeats, the second most common repeat type in the human genome, particularly neglected due to the difficulty of accurately determining their lengths [reviewed in (Ellegren, 2004, Zavodna et al., 2018)). We do know that STRs are highly mutable, with a reported mutation rate of $10^{-4}$ to $10^{-3}$ insertion/deletions (indels) per nucleotide per generation, partly dependent on repeat length, motif type, and repeat purity (Fungtammasan et al., 2015, Sun et al., 2012). The widelyaccepted mechanism proposed to explain this instability invokes a slippage mechanism, in which STRS gain or lose repeats due to strand slippage during replication (Sia et al., 1997). However, STRs are not just unstable during replication, but also during meiotic and mitotic homologous recombination and post-replication DNA repair, implying additional mechanisms beyond the simple slippage model [reviewed in (Richard et al., 2008, Bagshaw, 2017)).

Though potentially an important factor in their evolution, STR instability in the context of meiotic recombination is still far from understood, and the existing evidence is patchy and conflicting among studies. Naively, if recombination is mutagenic for STRs we would expect a positive correlation between STR variation and recombination. Early work found that broad scale recombination rates, however, were at most weakly correlated (Kong et al., 2002, Jensen-Seaman et al., 2004, Payseur and Nachman, 2000), though a more recent study found a slight positive correlation, with the strongest effect observed for mono- and dinucleotides (Mallick et al., 2016). A study using fine-scale maps of recombination hotspots suggested that recombination itself may only weakly drive this correlation, instead implicating local base composition (Brandstrom et al., 2008).

Nevertheless, the link between STRs and recombination merits further study, since several lines of evidence suggest that meiosis affects repeat instability. In particular, meiotic recombination is the most frequent destabilizing process for minisatellite repeats (unit size 15-100 bp) (Bois and Jeffreys, 1999, Jeffreys et al., 1998, Bishop and Schiestl, 2000). Moreover, meiotic recombination and some 
STRs, especially poly-As, may be functionally related. Certain STRs or STR containing motifs, including poly-As, are overrepresented in human (Myers et al., 2005), yeast (Bagshaw et al., 2008), and Arabadopsis (Choi et al., 2013, Wijnker et al., 2013, Horton et al., 2012, Choi et al., 2018) recombination hotspots [reviewed in (Tiemann-Boege et al., 2017)]. The interpretation of these findings, however, is confounded by the overlap between recombination hotspots and transcription sites in the latter two species. Nevertheless, direct experimental evidence suggests that repeats can promote recombination activity: deletion of a poly-A in one hotspot in yeast reduced meiotic conversion activity (Schultes and Szostak, 1991), while an introduced GT dinucleotide repeat increased recombination (Treco and Arnheim, 1986). The presence of repeats can also interfere with recombination, as seen for an introduced long GT repeats which inhibited crossover (CO) formation, and the repeat itself was highly unstable (Gendrel et al., 2000).

In addition, meiotic gene conversion has been implicated as an important driver of STR evolution, in particular, for disease-causing trinucleotide microsatellite (Jankowski et al., 2000). In fact, meiotic gene conversion may affect all indels, not just STRs. Gene conversion biases appear to favor the long over the short allele in small indels (insertion-biased gene conversion; iBGC) (Leushkin and Bazykin, 2013, Ometto et al., 2005, Presgraves, 2006). In contrast, the analysis of COs and non-crossovers (NCOs) of a very large human pedigree showed that the shorter allele was transmitted more often than the longer one in gene conversions (Halldorsson et al., 2016). A bias towards the shorter allele was also reported for non-allelic gene conversions in Drosophila (Assis and Kondrashov, 2012). Since none of these studies differentiate between the type and length nor the nature of the indel (e.g. repeat type), it is difficult to compare and interpret the different trends between studies.

STR instability in the context of meiotic recombination has been underexplored, and thus, models are incomplete, especially for mononucleotide repeats. Here, we screened thousands of single CO and NCO products from a human recombination hotspot using pooled sperm typing and characterized the transmission of two polymorphic poly-A repeats. We explored the effect of these STRs on CO and NCO rates, and on biases of allelic transmission by gene conversion. Our high-resolution data set provided important insights in the effect of length asymmetry and heterozygosity of STRs in doublestrand break (DSB) repair and aided to detangle the complex relationship between STR instability and meiotic recombination.

\section{Results}

\section{Hotspot features dissected with pooled sperm typing}

We analyzed the sequence of single meiotic products from a human recombination hotspot located on chromosome 16 within the RBFox 1 intron (hotspot HSII) with an average SNP density of 4 
SNPs/kb. There are three poly-A repeats in the vicinity (6A/7A, 9A/19A, and 23A) located $-493 \mathrm{bp}$, $157 \mathrm{bp},+236 \mathrm{bp}$ from a central PRDM9 motif at chromosome position 6,361,060 (GRCh37/hg19) (Figure 1A). Single meiotic products were collected using pooled sperm-typing as previously described (Arbeithuber et al., 2015, Tiemann-Boege et al., 2006). This method amplifies single CO or NCO molecules in aliquots containing low concentrations of sperm DNA by allele-specific, nested quantitative PCR (qPCR). $C O$ and NCO products were collected based on similar principles, with the main difference in the initial primer set-up (Figure 1B). Briefly, to retrieve COs, we used nested PCR with two flanking pairs of allele-specific PCR primers targeting four informative (heterozygous) SNPS, two on each side of the hotspot. This design preferentially amplified single CO products that were then characterized by genotyping heterozygous internal SNPS with allele-specific PCR or TaqMan ${ }^{\oplus}$. To collect NCOs, we selectively amplified only one of the two homologues using external flanking SNPS, followed by a second allele-specific qPCR targeting internal informative SNPs.

We recovered eight informative donors that were either heterozygous $(\mathrm{Ht} ; 9 \mathrm{~A} / 19 \mathrm{~A})$ or homozygous (Ho; 19A/19A) for one of the central poly-As (SM-Table 1). We were not able to collect recombinant molecules from $6 \mathrm{~A} / 6 \mathrm{~A}$ or $9 \mathrm{~A} / 9 \mathrm{~A}$ Ho donors, since this genotype was linked only to homozygous flanking-markers that are inadequate for our pooled sperm typing assay. We verified that our donors, all of European descent, are carriers of the most common Westeurasian allele of PRDM9 (variant A), a trans-acting factor that determines the placement of DSBs at the onset of meiosis [reviewed in (Tiemann-Boege et al., 2017)]. COs and NCOs for both reciprocal products were characterized in these eight different donors, and we collected in total 4,448 COs from 3,948,418 amplifiable meiosis and 246 NCOs from 360,474 amplifiable meiosis (SM-Table S2).

We estimated the location of the hotspot center from our $\mathrm{CO}$ and NCO data as the region with the highest concentration of breakpoints, which lies within a hotspot estimated from linkage disequilibrium data (International HapMap et al., 2007) and DSB maps of PRDM9 ${ }^{A}$ carriers (Pratto et al., 2014) (Figure 1A; SM-Figure S1-6). The estimated CO center lies in close proximity to the PRDM9 ${ }^{A}$ binding site (280 bp). The average NCO center is also very close to this central PRDM9 binding site (200 bp; SM-Table S3); although the exact location of NCO centers is more ambiguous and based only on a few SNPs and smaller sample sizes. Three additional canonical PRDM9 binding motifs occur within our hotspot, but this central binding site is the most active one (Altemose et al., 2017). Thus, we assume that the majority of the DSBs occur at or in close proximity to this central PRDM9 motif (highlighted throughout the figures), and that the repair and resolution of the DSB into COs or NCOs develops in the vicinity of the two long poly-As (9A/19A and 23A).

Interestingly, H3K4me3 (a nucleosome mark observed in active hotspots), as measured in human spermatocytes (Pratto et al., 2014) and PRDM9 ${ }^{A}$ transfected cells (Altemose et al., 2017), is lowest at 
140 the sites harboring the longer poly-A repeats $(9 A / 19 A$ and $23 A$ ), located $\sim 160$ or $\sim 240$ bp from the

141 most active PRDM9 binding site, respectively (Figure 1C). This pattern is unusual: typically, H3K4me3

142 at hotspots is lowest at the PRDM9 binding site and highest 150-250 bp upstream and downstream

143 from it (Lange et al., 2016, Baker et al., 2014, Powers et al., 2016) and [reviewed in (Paigen and

144 Petkov, 2018)]. The observed H3K4me3 patterns in our hotspot can be explained by the effect of

145 poly-As on nucleosome occupancy. Poly-A tracts resist nucleosome binding, which requires sharp

146 bends in DNA that destroy purine-purine stacking and the zig-zag structure of additional non-Watson-

147 Crick hydrogen bonds (Nelson et al., 1987). As a result, poly-A repeats show poor nucleosome

148 occupancy, with longer repeats showing more extreme depletion (Field et al., 2008, Segal and

149 Widom, 2009). The two longer poly-A runs (9A/19A and 23A) in our hotspot probably have low

150 affinities for nucleosomes and thus reduced levels of H3K4me3. It is also possible that the open

151 chromatin structure resulting from nucleosome depletion at these sites makes the PRDM9 motif

152 closest to the poly-As more accessible for binding than the other nearby motifs.

The 9A/19A STR influences the recombination outcome of CO or NCO

154

155

156

157

158

159

160

161

162

163

164

165

166

167

168

169

170

171

172

173

We estimated a mean recombination frequency of $79 \mathrm{cM} / \mathrm{Mb}$ at HSII, similar to the HapMap value of $\sim 63 \mathrm{cM} / \mathrm{Mb}$ obtained from linkage disequilibrium data (International HapMap et al., 2007). We asked whether the central asymmetric 9A/19A repeat influences DSB repair and the outcome into CO or NCO. We found that outcomes differ significantly between 9A/19A Ht and 19A Ho donor groups (Figure 2 and SM-Table S2). There was an approximately two-fold decrease in Co events in the 9A/19A Ht vs. 19A Ho group (exact two-sided Poisson test, EPT, Ht:Ho rate ratio $0.6 \pm 95 \% \mathrm{Cl}(0.6$ 0.7), $p<2.2 \mathrm{e}-16)$. Conversely, NCO events in $\mathrm{Ht}$ vs. Ho donors increased by roughly two- to three-fold (Ht:Ho rate-ratio $2.2 \pm(1.7-2.9), p<3 e-10)$. Furthermore, the overall recombination frequency (sum of $\mathrm{CO}$ and $\mathrm{NCO}$ ) is reduced by $17.8 \%$ in the $\mathrm{Ht}$ donors $(p<2 \mathrm{e}-16$; Figure $2 \mathrm{~B}$ ). Interestingly, while several studies have reported that NCOs typically outnumber COs, with the ratio of events ranging from 1 to 15 (Odenthal-Hesse et al., 2014, Jeffreys and May, 2004, Williams et al., 2015, Cole et al., 2014), we found an excess of CO over NCOs in our hotspot, even in the Ht donors (CO:NCO frequency $=2.0$ in $\mathrm{Ht}$ donors and 6.2 in Ho donors).

\section{Polymorphic STRs influence allelic transmission patterns}

We next examined the segregation of alleles by comparing recombination products for both reciprocals. According to Mendel's law of equal segregation, on average the alleles on each homologue are transmitted equally. However, during recombination, heterozygotes sites of paired homologues form a heteroduplex; repair of these heteroduplex sites results in gene conversions in which one of the two alleles is removed. If the repair is biased, this process can lead to a higher transmission frequency of one allele over the other. Such biased repair underlies GC-biased gene 
conversion ( $\mathrm{gBGC}$ ), the over-transmission of 'strong' $\mathrm{G} / \mathrm{C}$ over 'weak' $\mathrm{A} / \mathrm{T}$ alleles, observed at hotspots in several species [reviewed in (Duret and Galtier, 2009, Lassalle et al., 2015, TiemannBoege et al., 2017)].

Here, we analyzed $g B G C$ by comparing the reciprocal alleles proximal and distal to the CO breakpoints of all collected COs in a contingency table analysis. Specifically, we used a Cochran Mantel Haenszel (CMH) framework to quantify the transmission advantage of heterozygous alleles as described previously (Arbeithuber et al., 2015). We calculated a significant excess of COs with strong alleles (rate-ratio of GC to AT alleles $=1.27 ; p<1 \mathrm{e}-4$ ), implying $\mathrm{GC}$ alleles are transmitted to $53 \%$ in sperm with a CO or $50.013 \%$ of all sperm in the tested donors (Table 1). The resulting transmission advantage due to $\mathrm{gBGC}(b)$ of $2.7 \times 10^{-4}$ is similar to that reported in another hotspot $\left(4.6 \times 10^{-4}\right)$ (Arbeithuber et al., 2015).

Interestingly, gBGC appears impeded by asymmetry at the 9A/19A STR: the Ho donor group had significantly stronger $\mathrm{gBGC}$ than the $\mathrm{Ht}$ group (Table $1 ; \mathrm{RR}_{\mathrm{Ho}}=1.5$, vs. $\mathrm{RR}_{\mathrm{Ht}}=1.1$, respectively). For NCOs, as well, gBGC is found in the Ho group, but not in the Ht group-- in fact, 9A/19A NCOs show a bias favoring weak alleles (Table 1). Inspection of the allelic transmission at individual polymorphic sites in CO ( $\log R R$ plots in Figure 3B and SM-Figure S7-12 B) suggests an explanation for this difference in $\mathrm{gBGC}$ between donor groups in CO: the 19A homologue and its flanking alleles are also over-transmitted; as 19A is mainly in phase with $\mathrm{A} / \mathrm{T}$ alleles, this effect overpowers the overall $\mathrm{gBGC}$.

Next, we examined the allelic transmission of heterozygous STRs. Overall, we observed that the longer allele was over-transmitted in $\mathrm{CO}$ in congruence with $\mathrm{BBGC}$ as shown in Table 1. For $\mathrm{CO}$, Analysis of individual STRs (9A/19A or 6A/7A) in each donor group showed a trend for the longer allele to be transmitted more often than the shorter one at each site (Table 1, Figure 3B and SMFigure S7-12 B). Interestingly, iBGC in COs is mainly driven by the 6A/7A STR, which showed a stronger iBGC than the asymmetric 9A/19A STR (RR $=1.95$ vs. 1.02 , respectively). Note that very few CO events occurred the $9 \mathrm{~A} / 19 \mathrm{~A}$ STR and $\mathrm{BBGC}$ at this site is not significant. Also, the $\mathrm{Ht}$ donors had better support for $\mathrm{BGGC}$ at the $6 \mathrm{~A} / 7 \mathrm{~A}$ STR site than the Ho group ( $\mathrm{RR}=1.95$ vs 1.56 , respectively).

For NCO, the transmission patterns support also the preference for the longer allele at the $6 \mathrm{~A} / 7 \mathrm{~A}$ STR, despite the scarcity of conversions here (Table 1). However, for the 9A/19A in NCO the trend is reversed, with the $9 \mathrm{~A}$ being transmitted significantly more often than the longer $19 \mathrm{~A}\left(\mathrm{RR}=0, p<10^{-6}\right.$ ) in all types of conversion events (simple NCOs, co-conversion, and complex conversion events). Overall, averaging over both COs and NCOs, we find insertion biased transmission at the 6A/7A site (recovered in 57.4\% of NCO and CO molecules, using FxR from Table 1 and the CO:NCO ratio from 
206

207

208

209

210

211

212

213

214

215

216

217

218

219

220

221

222

223

224

225

226

227

228

229

230

231

232

233

234

235

236

237

238

Table S2), whereas we see deletion biased transmission at the 9A/19A site $(45.2 \%$ of NCO and CO molecules).

\section{The 9A/19A STR reduces $C O$ exchanges and increases complex conversions}

The repair of meiotic DSBs is expected to result in a new arrangement of phased alleles in both CO and NCO. For both $\mathrm{CO}$ and NCOs, recombination breakpoints are expected to accumulate near the DSB site, with the exact breakpoint determined by the extent of repair near the DSB (Jeffreys et al., 2001, Jeffreys and May, 2004, Odenthal-Hesse et al., 2014, Tiemann-Boege et al., 2006, Arbeithuber et al., 2015). The exchange points in our hotspot (Figure 3 and SM-Figure S7-12) also show this pattern, except for the asymmetric 9A/19A STR in Ht donors. Instead, the Ht donor group shows a unique pattern with reduced or absent $\mathrm{CO}$ exchange points directly at the 9A/19A in the middle of the hotspot (Figure 3A and SM-Figure S7-8 A). We observed this pattern for all three Ht donors that were informative for several closely spaced SNPs in this region (3 out of $4 \mathrm{Ht}$ donors). Such "gaps" in CO breakpoints have been previously observed at positions of palindromic repeats, and long and complex micro- or even minisatellites with inversions in mice (Cole et al., 2010, Baudat and de Massy, 2007, Wu et al., 2010) and humans (Jeffreys and Neumann, 2005), but not in the context of an asymmetric mononucleotide run. Here, this $\mathrm{CO}$ gap is instead caused by a relatively minor length polymorphism of $10 \mathrm{bp}$ within a perfect poly-A mononucleotide repeat.

The analysis of NCO events shows that most conversions ( $83 \%$, SM-Table S6) involve only one SNP with an estimated mean tract length of $1037 \pm 1264$ bp (SM-Table S7) for all eight donors, with no difference in tract length between donor groups. Conversions involving a single SNP are not unusual and were initially observed in several mice hotspots, which had higher SNP densities than our donors (Cole et al., 2010), and have also been previously observed in humans (Odenthal-Hesse et al., 2014). Despite the lower density of informative SNPs in our hotspot, we identified $\sim 4 \%$ of co-conversions involved 2 SNPs, but a few also spanned over 3 SNPs ( 1\%; SM-Table S6).

Interestingly, we also observed that $\sim 12 \%$ of the NCO involved complex conversions (SM-Table S6) with tract lengths of $1543 \mathrm{bp} \pm 793 \mathrm{bp}$ that carried unconverted SNPs between converted ones (Figure 3E-F and SM-Figure S7,9-11 E-F). This is the first report of such complex conversion tracts within such a short distance. Complex conversion tracts have been reported over much longer distances of $100 \mathrm{~kb}$ (Halldorsson et al., 2016) and $12 \mathrm{~kb}$ (Williams et al., 2015). In most complex conversions, only a single SNP was unconverted (Figure 3E-F and SM-Figure S7,9, 10-11 E-F), which involved in all cases the 9A/19A STR and/or flanking SNPs to this STR. Of note is the significant 3-fold higher frequency of these complex conversions in the Ht over the Ho donor group per amplifiable meiosis, in which the 9A is the unconverted allele (SM-Figure S13 and SM-Table S8). These complex 
conversions explain the highly significant deletion bias observed at the $9 \mathrm{~A} / 19 \mathrm{~A}(\mathrm{RR}=0.00 ; p<1 \mathrm{e}-6)$ favoring the transmission of the $9 \mathrm{~A}$ over the 19A (Table 1).

We also observed complex $\mathrm{COs}(\mathrm{CCO})$ in both $\mathrm{Ht}$ and $\mathrm{Ho}$ donor groups occurring at similar frequencies (1.6\% and $1.2 \% \mathrm{CCO} / \mathrm{CO}$ or $3.5 \mathrm{E}-05$ and $4.3 \mathrm{E}-05 \mathrm{CCO} /$ meiosis, respectively; Table S8-9; SM-Figure S13). Approximately 70\% of the complex tracts were located upstream of the 9A/19A STR or directly at the STR position and only $\sim 30 \%$ were located directly after the STR position. The frequency of $\mathrm{CCO}$ was $\sim 3$ times higher than reported for other hotspots $(\mathrm{CCO} / \mathrm{CO}=0.35 \%, 0.21-0.54$ ) (Arbeithuber et al., 2015) and 0.33\% (Webb et al., 2008).

Poly-As are enriched in recombination hotspots, but are not more diverse

Given the strong iBGC in our hotspot for the short poly-A $(6 \mathrm{~A} / 7 \mathrm{~A})$, we examined genomic data for signatures of enrichment of poly-A's at hotspot locations. Specifically, we retrieved the genomic coordinates of all poly-As with perfect repeat tracts of 6 or more As from the reference genome (GRCh37/hg19). We then compared the enrichment of poly-As in recombination hotspots, in hotspotflanking regions of 1-kb sliding windows (5 windows in total), and in the rest of the genome by dividing the total number of poly-As counted in each zone with the corresponding zone length. Figure 4A shows that hotspots are enriched for poly-As compared to flanking regions, but not compared to regions outside the hotspot neighborhood ( $>5 \mathrm{~kb}$ away). For further analysis, we limited our comparisons to hotspots and flanking regions, given their similar genomic contexts (Figure 4B-D). We observed a significant $~$ three-fold increase of poly-A enrichment and density of As within a repeat in hotspots compared to flanking regions (Figure 4B), which was consistent throughout the range of tract lengths (Figure 4C and D). Regardless of location, the number of poly-As decayed rapidly with tract length (Figure 4C), with 90\% of the poly-As being 6-11 nucleotides in length (mean $=7.77$, median $=6$ ) in hotspots and flanking regions. Similar patterns were also observed for poly-Ts (SMFigure S14).

We also tested for an effect of hotspots on the diversity of poly-As, as would be expected if these poly-As are more unstable than poly-As more distant from a hotspot. For this analysis, we used the lobSTR reference sites from the Simons Genome Diversity Project (SGDP) (Mallick et al., 2016) that were variable in individuals of Westeurasian descend (likely PRDM9 ${ }^{A}$ carriers). Most poly-As, whether in hotspots or flanking regions, had an average of three alleles per site, with only one nucleotide difference between repeats. We tested four estimates of diversity: heterozygosity, allelic asymmetry (difference between the longest and shortest allele), steps between alleles (unit differences between alleles), and the total number of different alleles in the population (see Materials and Methods for details). None of the diversity measures showed any difference between poly-As in hotspots and 
273 flanking regions. Moreover, we observe no difference in asymmetry between major alleles in 274 hotspots compared to flanking regions (SM-Figure S15). Interestingly, in this data set we also 275 observed poly-A enrichment of 1.5-2-fold bordering on significance. Moreover, this enrichment 276 decreased rapidly with tract length, and was almost absent with poly-As greater than 23 As (SM277 Figure S16). Since lobSTRs were only called for poly-As with 11 to $\geq 26$ As, we repeated this analysis 278 with poly-As from the genome reference restricted to the same lengths, showing this time a 279 significant 3-fold enrichment at hotspots as described in Figure 4 (SM-Figure S17).

280 Given the strong iBGC and insertion mutation bias, a lack of an increase in variability of poly-As at hotspots is surprising. However, it is possible that a sample size larger than our tested SGDP population is required to obtain a measurable effect (with a transmission frequency of $50.004 \%$, only 7 sites are expected to expand in the 175,384 poly-A sites retrieved from the SGDP, see Table 1). In fact, a slight positive association was described previously when comparing heterozygosity with broad scale recombination, yet considering all mononucleotides (Mallick et al., 2016).

\section{Discussion}

\section{STR lenqth asymmetry influences DSB repair}

Meiotic recombination is initiated by programmed DSBS via SPO11, followed by a series of repair steps from strand resection to invasion, the formation of complex intermediate structures between homologs, and the repair of mismatches of heteroduplexes in paired homologue strands (Figure 5). The intermediate structures can be repaired either by double strand break resolution (DSBR) leading mainly to COs and NCOs, or by synthesis-dependent strand annealing (SDSA), resulting in NCOs [reviewed in (Arnheim et al., 2007, de Massy, 2013, Paigen and Petkov, 2010, Tiemann-Boege et al., 2017, Lam and Keeney, 2014)]. In our analysis of thousands of CO and NCO products from two different donor groups (9A/19A Ht and 19A/19A Ho), we observed that the length asymmetry of 10 nucleotides between the homologous alleles $(9 \mathrm{~A} / 19 \mathrm{~A})$ at the center of the hotspot and in close proximity to the DSB site ( $160 \mathrm{bp})$ reduces the number of DSBs repaired as COs. These are alternatively repaired as NCOs. Also, the $9 \mathrm{~A} / 19 \mathrm{~A}$ asymmetry slightly reduced the overall recombination frequency, and resulted in other events such as larger conversion tracts leading to reduced $\mathrm{gBGC}$, central gaps in $\mathrm{CO}$ exchanges at the asymmetric site, and a higher frequency of complex conversion events.

Why a length asymmetry in STRs shifts the fate of DSBs and influences its own exchange and that of flanking SNPs is not known, but it could be linked to the formation of DNA loops at the heteroduplex 9A/19A STR site (Figure 5). These structures are likely temporary slipped structures, as are predicted for misaligned repeats [reviewed in (Wang and Vasquez, 2006)]. Similar outcomes have been 
reported for stable loops at recombination hotspots: reduced exchange between homologues at the loop site, so called "exchange gaps" were observed in the context of inverted repeat structures of $\sim 140 \mathrm{bp}$ (Cole et al., 2010), indels of 20-50 bp in mice (Baudat and de Massy, 2007, Wu et al., 2010, Paigen et al., 2008, Bois, 2007), at indel positions in A.thaliana (Drouaud et al., 2013), and at the palindromic AT-rich minisatellite MSNID in humans (Jeffreys and Neumann, 2005). Two of these studies also reported an increased NCO frequency at these sites, similar to that seen here (Jeffreys and Neumann, 2005, Cole et al., 2010).

Note, however, that unlike the structures in these studies, which form large and stable loops (e.g. hairpin loops or cruciform structures, in the case of the inverted repeat), simple poly-As do not form stable secondary structures (Snyder et al., 2008). It is thus surprising that a 10 bp mismatch is sufficient to trigger a similar exchange gap. Large, stable structures can impair or even prevent strand invasion and exchanges within the minisatellite (Jeffreys and Neumann, 2005), or also attract nucleases that remove the loop and produce longer conversion tracts (co-conversions) (Cole et al., 2010). In addition, inverted repeats or palindromes capable of forming stable hairpins or cruciform structures at recombination hotspots have been reported to result in promiscuous, SPO11 independent, DSBs and large, deleterious chromosomal rearrangements [e.g. non-Robertsonian translocations reviewed in (Richard et al., 2008)].

Another phenomenon observed in our $\mathrm{Ht}$ 9A/19A donor group was the slight, but significant reduction in the overall number of recombination products $(\mathrm{CO}+\mathrm{NCO})$. This reduction might be explained by two different possible processes: 1) an altogether lower number of DSBs in Hts, and/or 2) an increased level of inter-sister repair in $\mathrm{Hts}$. A reduction in DSBs linked to mismatches has been previously reported for strong asymmetric heterozygous deletion sites; e.g. a 176 bp and 279 bp deletion (Rocco and Nicolas, 1996) or a $\sim 1 \mathrm{~kb}$ deletion at the ARG4 region in yeast (Xu et al., 1995). Differences in open vs. closed chromatin states also influence DSBs formation in yeast (Ohta et al., 1994). Based on a previous report which estimated that a 19 bp poly-A has $\sim 3$-fold less nucleosome occupancy than a $9 \mathrm{bp}$ poly-A (Field et al., 2008), we hypothesize that the poly-A length asymmetry in our hotspot at the 9A/19A site leads to differences in the chromatin state between homologues; however, it is difficult to assess if this difference in nucleosome occupancy between homologues already affects DSB formation.

\section{How are heterozygous STRs repaired?}

Although we cannot extrapolate the expected trends for all levels of asymmetry or types of STRs from our data, our results suggest that length asymmetries (e.g. 9A/19A) forming temporary loop structures trigger a series of alternative repair pathways. Single nucleotides or 1-2 bp indels are 
recognized by the MSH2-MSH6 complex of the mismatch repair (MMR) system, whereas longer indel loops attract MSH2-MSH3 in humans [reviewed in (Spies and Fishel, 2015)] and yeast [reviewed in (Chakraborty and Alani, 2016, Manhart and Alani, 2016)]. The MMR complex initiates repair in 5' or 3' direction starting from a nick or strand break [reviewed in (Jiricny, 2006)], with the efficiency of repair decreasing proportionally with increasing loop sizes (Jensen et al., 2005, McCulloch et al., 2003a). For large loops, an alternative repair system, known as large loop-repair (LLR), is likely active instead of MMR. LLR activity has been described for MMR-deficient cells in yeast (Corrette-Bennett et al., 2001, Kirkpatrick and Petes, 1997) and human cells (McCulloch et al., 2003b). LLR starts the repair either from a nick or a gap in $5^{\prime}$ - or $3^{\prime}$ - direction (nick-directed repair), similar to MMR, or simply removes the loop via endonucleolytic cleavage (loop-directed repair), regardless if the loop is located at a nicked strand or not (McCulloch et al., 2003b). Loop-deletion or -retention depends mainly on the length and secondary structure of the loops (Bill et al., 2001). Short palindromic loops are preferentially retained (12 and $14 \mathrm{bp}$ loops), whereas longer palindromic loops (40 bp) are removed (Bill et al., 2001), and sometimes palindromic loops are not repaired (Corrette-Bennett et al., 2001). In comparison, non-palindromic loops are preferentially removed independent of their size (Bill et al., 2001) and these unstructured loops (e.g. temporary loops like our asymmetric poly-A) are repaired with an efficiency of over $90 \%$ (Corrette-Bennett et al., 2001). The current model proposes that small loops (2-16 bp) are repaired by both LLR and MMR, but as loops get larger, LLR is the most prominent mechanism (Jensen et al., 2005, McCulloch et al., 2003a, Corrette-Bennett et al., 2001, Sommer et al., 2008).

It cannot exactly be elucidated from our data which of the repair processes are acting on the temporary loops at the asymmetric 9A/19A STR, but certain trends can be recognized. It is possible that both homologues are equally targeted for DSBs based on the absence of PRDM9 motif differences between homologues and equal frequency of observed reciprocal NCOs (SM-Table S5). However, given the higher nucleosome occupancy and thus, also higher H3K4me3 levels (a required signal recognized by the DSB machinery) at the homologue carrying the shorter poly-A (9A), we cannot discard that this homologue could be the preferred DSB target. In fact, the over-transmission of SNPs located 130-560 bp upstream of the STR linked to the 19A homologue can be best explained by a scenario that starts with a DSB in the 9A homologue. The mismatch at the STR is then repaired either by LLR or MMR, directed by introducing a second 5'-3' nick which results in a larger DSB gap, as it was also suggested in a mouse hotspot for an inverted repeat forming a stable secondary loop (Cole et al., 2010)). In contrast, DSBs in the 19A homolog are likely repaired only by LLR, which removes the loop, resulting in no over-transmission of $5^{\prime}$ flanking SNPs, since longer loops $>16$ bp are processed only in $3^{\prime} \rightarrow 5^{\prime}$ direction (McCulloch et al., 2003a). 
Support for active LLR in our hotspot also comes from our observation of complex conversions mostly carrying the short 9A allele, likely the result of more loop-deletions than retentions, as proposed for non-palindromic structures (Bill et al., 2001). Further, the fact that complex crossovers mainly occurred upstream of the 9A/19A STR supports an active LLR. However, we cannot exclude that intersister repair instead resulted in these complex conversions, as observed in (Halldorsson et al., 2016, Williams et al., 2015, Tsaponina and Haber, 2014). Although unusual, evidence of inter-sister repair of DSBs was shown in 13-25\% of repair tracts in S. cerevisiae (Schwacha and Kleckner, 1994, Schwacha and Kleckner, 1997, Oh et al., 2007, Jessop and Lichten, 2008). Moreover, CAG tracts, as well as inverted repeats, induce inter-sister recombination in yeast (Nag et al., 2004). Especially in regions of high heterozygosity (e.g. insertion/deletions), the repair of DSBs via the sister in addition to the homolog ensures timely DSB repair (Goldfarb and Lichten, 2010). The overall lower total recombination frequency observed in $\mathrm{Ht}$ donors could also indicate possibly active inter-sister repair. Alternatively, other pathways like micro-homology mediated end-joining or single strand annealing leading to deletions could also explain our NCO data [reviewed in (Polleys et al., 2017)].

\section{STRs with small asymmetries lead to iBGC}

The analysis of STR mutations in human pedigrees suggests that STR instability models should incorporate length asymmetry and heterozygosity (Amos et al., 2015). Our results support this view and clearly suggest that factors like length asymmetry, heterozygosity, and the location of the polyAs at recombination hotspots play an important role in their transmission and evolution. The heterozygosity and asymmetry at the 9A/19A at the hotspot center supports a deletion bias (overtransmission of the shorter allele), whereas the heterozygous 6A/7A STR with only one mismatch located $200 \mathrm{bp}$ from the hotspot center supports an insertion bias (the longer allele is overtransmitted; Table 1). The transmission of the $9 \mathrm{~A} / 19 \mathrm{~A}$ is subject to LLR processing resulting in recombination outcomes favoring the shorter allele, especially in complex NCO. In contrast, the outcome of repair at the 6A/7A site is likely the result of MMR acting on heteroduplexes formed in later steps of meiotic DSB repair, as proposed also for gBGC in yeast (Lesecque et al., 2013) and in human (Glemin et al., 2015). MMR preferentially replaces the shorter for the longer allele in Drosophila (Leushkin and Bazykin, 2013, Ometto et al., 2005, Presgraves, 2006), as we also observed for the 6A/7A STR. Interestingly, the observed iBGC at the 6A/7A site is larger than our estimated gBGC for strong vs. weak SNPs in our hotspot ( $R R=1.9$ vs. 1.3 , respectively).

A deletion bias was reported for $\mathrm{COs}$ and NCOs derived from of a very large pedigree study (Halldorsson et al., 2016) and also for non-allelic gene conversions in Drosophila whole genome 
407

408

409

410

411

412

413

414

415

416

417

418

419

420

421

422

423

424

425

426

427

428

429

430

431

432

433

434

435

436

437

438

439

sequence comparisons (Assis and Kondrashov, 2012). A study that stratified indels into different lengths also observed a transmission bias favoring deletions associated with recombination in humans, flies, and yeast (Leushkin and Bazykin, 2013). However, for small indels (1-4 bp) the trend was reversed, with a insertions favored instead, with the strongest bias measured for indels with $1 \mathrm{bp}$ difference ( $\sim 5$-fold higher insertion over deletion rate; (Leushkin and Bazykin, 2013). While (Leushkin and Bazykin, 2013) measured an indirect statistical association between indel mutation rates and recombination rates in different organisms which have recombination maps of varying resolution ( $\mathrm{Mb}$ to $\mathrm{bp}$ ), their findings are consistent with our model proposing that at recombination hotspots heterozygous STRs with small asymmetries expand, while STRs with large asymmetries contract. In a broader context, repair at heterozygous STRs requires an extra round of DNA synthesis to remove the slipped DNA at the heteroduplex, which may introduce new mutations by error-prone polymerases active in MMR, explaining the observation of increased single-nucleotide changes flanking indels (Tian et al., 2008).

\section{Seeking for the hidden - poly-A enrichment at human recombination hotspots}

Given the strong $i B G C$ in our hotspot for the short poly-A (6A/7A), we predict that over evolutionary time hotspots become enriched with poly-As. Nucleotide composition at evolutionary equilibrium (described by the Li-Bulmer equation 1/[1+ $\kappa\left(\exp \left(-2 N_{e} b\right)\right]$, (Bulmer, 1991, Nagylaki, 1983)), can be estimated considering a heterozygous selection coefficient favoring insertion over deletions (equivalent to the $\mathrm{iBGC}, b$ ), the effective population size $N_{e}$, and the ratio of the opposing mutation rates, $\kappa$ (in/del vs del/in). Since there are no published indel mutation rates for individual poly-A lengths in humans, we extracted this data from a pedigree analysis (Fungtammasan et al., 2015). For repeats between $6-12 \mathrm{As}$, the insertion rate is more frequent than the deletion rate (SM-Table S10); (Sun et al., 2012), but this trend is reversed for longer poly-As (>12As). Given that indel mutational bias changes with repeat length, the transmission pattern depending on heterozygosity and repeat asymmetry, makes the prediction on the outcome of poly-A evolution at hotspots rather complex. For short repeats, however, a back-of-an-envelope calculation shows that strong iBGC combined with a mutation bias favoring insertion predicts an enrichment of short to intermediate sized poly-As $\quad<12$ bp) at hotspots, consistent with the observed enrichment of poly-As at hotspots compared to flanking regions. Similar findings from an analysis of STRs other than mononucleotide repeats in yeast also show a two-fold enrichment of STRs near DSBs and recombination hotspots. The biological mechanisms driving this enrichment is unlikely to be mutagenesis, given the lack of de novo STR mutations measured at hotspots (Zavodna et al., 2018). 
440 However, it could be possible that the cause of the observed poly-A enrichment at hotspots is due to

441 inherent DNA properties of poly-As promoting the formation of recombination hotspots, and not the

442 consequence of $\mathrm{iBGC}$ and insertional mutation bias. That is, as poly-As expand, they lose nucleosome

443 occupancy creating open chromatin regions that extend beyond the poly-A tract by at least one

444 hundred base pairs [reviewed in (Segal and Widom, 2009)], possibly increasing the accessibility of the

445 DNA by PDRM9. Moreover, independent of PDRM9, open chromatin is expected to facilitate

446 homologous invasion, a key process for synapsis. In fact, poly-A enrichment at hotspots is also

447 observed in species that lack this enzyme, such as plants (Choi et al., 2013, Choi et al., 2018, Wijnker

448 et al., 2013, Horton et al., 2012) and yeast (Bagshaw et al., 2008), with the latter species enriched for

449 poly-A runs $\geq 14$ bp at hotspots (Bagshaw et al., 2008) and reviewed in (Tiemann-Boege et al., 2017).

450 Distinguishing whether poly-A enrichment is a direct consequence of recombination and not vice

451 versa would require further testing. However, our analysis also shows that poly-As become

452 increasingly rare with length, an indication that the unlimited expansion of poly-As is constrained.

\section{Conclusions}

454 How poly-As evolve in the context of meiotic recombination is largely understudied generally, 455 although of crucial interest also in the context of cancer research and gene regulation. Here we 456 provided direct experimental evidence that length asymmetry and heterozygosity play a key role in 457 the transmission and evolution of different poly-As at hotspots. For short poly-As, strong meiotic 458 conversion bias predicts their expansion. The density of longer As in hotspots, however, rapidly 459 decays with repeat length suggesting that an unlimited expansion is countered by some mechanism, 460 likely alternative repair pathways (MMR vs. LLR) that are activated when repeats become too long 461 and might form asymmetric loops. Thus, the exact processes that drive poly-A evolution change in 462 nature and effect with repeat length.

\section{Materials and Methods}

\section{Sample collection and DNA extraction}

466 Human sperm samples were collected from anonymous donors all of European (Austrian) descent at 467 the IVF clinic of the MedCampus III in Linz/Upper Austria approved by the ethics commission of 468 Upper Austria (F1-11). DNA extraction was performed with the Gentra Puregene Cell Kit (Qiagen) in 46996 well plate format for identification of informative donors or in single tubes for recombinant 470 collection. DNA extractions were from a defined number of sperm cells, $\sim 10^{6}$, as described in 471 (Arbeithuber et al., 2015).

\section{Identification of informative donors}

473 To find informative donors (heterozygotes), SNPs with a high heterozygosity (according to dbSNP 474 (Sherry et al., 2001)) within 1,000 bp flanking region of the recombination hotspot were selected 
and allele-specific primers were designed. All our analyses were based on the chromosome assembly GRCh37/hg19. SNPs rs $7201177 \mathrm{C} / \mathrm{G}$ and rs $1861187 \mathrm{C} / \mathrm{T}$ upstream, and rs4786854 C/T and rs4786855 $\mathrm{A} / \mathrm{C}$ downstream the hotspot (flanking SNPS) were chosen for collection of recombinant molecules (Primer table in SM-Material and Methods section 1).

Genotyping reactions were performed as described previously (Heissl et al., 2017, Arbeithuber et al., 2015, Tiemann-Boege et al., 2006) with small modifications. In short, in a total volume of $10 \mu \mathrm{l}$ including $0.125 \mathrm{U}$ OneTaq DNA Polymerase (NEB), 1x OneTaq Reaction Buffer (NEB), $0.2 \mathrm{mM}$ dNTPs (Biozym), 1x SYBR Green I in DMSO (Invitrogen), $0.2 \mu \mathrm{M}$ allele specific primer and $0.2 \mu \mathrm{M}$ outer primer (both Eurofins) and $10 \mathrm{ng}$ total genomic DNA were used for genotyping assays. Each SNP required two separate reactions for the individual alleles. For PCR details see SM-Material and Methods section 1.

Informative donors were haplotyped to determine the phase of the alleles using long-range allelespecific PCR (SM-Material and Methods section 2; (Arbeithuber et al., 2015, Arbeithuber et al., 2017, Tiemann-Boege et al., 2006)). In short, all 16 possible combinations of allele-specific primers were tested, with those primer pairs rendering an amplification product representing the phase of the four flanking SNPs. PCRs were set up in a volume of $10 \mu$ l containing $0.35 \mathrm{U}$ of Expand ${ }^{\mathrm{T} M}$ Long Range Polymerase (Sigma Aldrich), 1x Expand ${ }^{\mathrm{TM}}$ Long Range Standard Buffer (Sigma Aldrich), $0.2 \mathrm{mM}$ Expand $^{\text {TM }}$ Long Range dNTPack dNTPs (Sigma Aldrich), $0.4 \mu \mathrm{M}$ allele-specific forward primer and 0.4 $\mu \mathrm{M}$ allele-specific reverse primer (both Eurofins), 1x SYBR Green I in DMSO (Invitrogen) and $50 \mathrm{ng}$ genomic DNA. Details are in SM-Material and Methods section 2.

Donors were also typed for their PRDM9 alleles (SM-Material and Methods 3 ).

\section{Collection of $\mathrm{CO}$ and $\mathrm{NCO}$ events}

Eight different donors were chosen for $\mathrm{CO}$ and NCO collection at HSII; four donors were heterozygous for the central STR rs200121160 9A/19A and four of them were homozygote for 19A. Seven donors were heterozygous for rs35094442 6A/7A and one was homozygous for 7A (SM-Table S1).

For the collection of single CO products, allele-specific primers for flanking SNPs were used in two rounds of nested PCR (SM-Material and Methods section 4) as previously described in (Arbeithuber et al., 2015, Tiemann-Boege et al., 2006). The reactions contained 0.1 U Phusion HSII (Biozym), 1x HF Buffer (Biozym), $0.16 \mathrm{mM}$ dNTPs (Biozym), $0.5 \mu \mathrm{M}$ allele-specific forward primer, $0.5 \mu \mathrm{M}$ allelespecific reverse primer (both Eurofins) and $800-1200$ molecules of genomic DNA for CO and 500 molecules for NCO collection (SM-Material and Method section 5). The $2^{\text {nd }}$ round of PCR contained $0.1 \mathrm{U}$ Phusion HSII (Biozym), 1x HF Buffer (Biozym), $0.16 \mathrm{mM}$ dNTPs (Biozym), 0.5x Eva Green (Jena Bioscience), $0.5 \mu \mathrm{M}$ allele-specific forward primer, $0.5 \mu \mathrm{M}$ allele-specific reverse primer (Eurofins) and $2 \mu \mathrm{l}$ of $1: 10$ diluted $1^{\text {st }}$ round PCR template for a total volume of $10 \mu$. The $2^{\text {nd }} P C R$ was exclusively performed for $\mathrm{CO}$ collection, whereas for NCOs the $1^{\text {st }}$ PCR product was directly used as genotyping template.

To control for technical artefacts, non-recombinants were amplified with a dilution of about 1-2 molecules per reaction with equivalent amounts of E.Coli DNA (4 ng) as carrier DNA. In addition, for each donor and reciprocal recombinant, we measured the number of amplifiable meiosis, which were used to correct the total number of meiosis determined spectrophotometrically in extracted sperm DNA. the correction factors across experiments were within 0.10-0.35 (SM-Table S11, and differed only slightly between donors and experiments). The total number of meiosis used per reaction was corrected by the effectively amplifiable number of meiosis for each donor.

\section{Genotyping of $\mathrm{CO}$ and NCO events}


519 COs were genotyped with TaqMan ${ }^{\oplus}$ PCR for the SNPs rs12102448 A/G, rs 112051149 C/T, rs72778219

$520 \mathrm{C} / \mathrm{T}$ and $\mathrm{rs} 8060928 \mathrm{C} / \mathrm{T}$. A total of $10 \mu \mathrm{l}$ were used containing $2 \mu \mathrm{l}$ of 1:1000 diluted 2 nd PCR product,

$5210.15 \mathrm{U}$ peqGold HotTaq Polymerase (peqlab), $3 \mathrm{mM} \mathrm{MgCl} 2,0.2 \mathrm{mM}$ dNTPs, $0.4 \mu \mathrm{M}$ forward primer,

$5220.4 \mu \mathrm{M}$ reverse primer, $0.2 \mu \mathrm{M}$ FAM labelled probe (allele 1) and $0.2 \mu \mathrm{M}$ HEX labelled probe (allele 2;

523 all Eurofins; SM-Material and Methods section 5). SNP rs12102452 A/C, rs35094442 6A/7A and the

524 rs200121160 9A/19A microsatellite were genotyped with allele-specific primers with $0.06 \mathrm{U}$ Phusion

525 HSIl polymerase (Biozym), 1x HF buffer (Biozym), $0.2 \mu \mathrm{M}$ dNTPs (Biozym), 1x SYBR Green I in DMSO

526 (Invitrogen), $0.4 \mu \mathrm{M}$ open forward primer, $0.4 \mu \mathrm{M}$ allele-specific reverse primer and $2 \mu \mathrm{l}$ of 1:1000

527 diluted 2nd PCR product (SM-Material and Methods section 6).

528 NCO were genotyped with iTaq DNA polymerase (BioRad) and Phusion HSII (Biozym) for the 9A/19A

529 microsatellite. For the iTaq protocol $10 \mu$ final volume containing $0.25 \mathrm{U}$ iTaq Polymerase (BioRad),

5301 1x reaction buffer (BioRad), $1.5 \mathrm{mM} \mathrm{MgCl}_{2}$ (BioRad), 1x SYBR Green I in DMSO (INVITROGEN), $0.4 \mu \mathrm{M}$

531 allele-specific forward primer, $0.4 \mu \mathrm{M}$ allele-specific reverse primer and $2 \mu \mathrm{l}$ of 1:10 diluted PCR

532 product were used. The genotyping of $9 A / 19 A$ microsatellite required $10 \mu l$ total volume containing

$5330.06 \mathrm{U}$ Phusion HSIl polymerase (Biozym), 1x HF buffer (Biozym), $0.2 \mu \mathrm{M}$ dNTPs (Biozym), 1x SYBR

534 Green I in DMSO (Invitrogen), $0.4 \mu \mathrm{M}$ open forward primer, $0.4 \mu \mathrm{M}$ allele-specific reverse primer and

$5352 \mu \mathrm{l}$ of 1:100 diluted PCR product (SM-Material and Methods section 6 and (Heissl et al., 2017)). Data

536 analysis was performed as described in SM-Material and Methods section 8.

\section{Data analysis}

538 Test for biased gene conversion. Statistical analysis of the CO and NCO data was performed using R v.

5393.3 (http://r-project.com), with Poisson tests using the exactci package v 1.3-3 and Cochrane-Mantel-

540 Haensel test with metafor 2.1-0. CO and NCO rates were checked for potential donor heterogeneity

541 with a Generalized Linear Model with a quasibinomial error model [Full model: (Number of CO/NCO

542 molecules, other molecules) donor identity + donor type $(\mathrm{Ht} / \mathrm{Ho})+$ type $(\mathrm{NCO} / \mathrm{CO})]$. As no

543 significant effect of donor was found, we instead used a simple Poisson test for the analysis.

544 Genome-wide poly-A analysis. We investigated the distribution of poly-As over the whole genome 545 using the full genome sequence for Homo sapiens as provided by UCSC (GRCh37/hg19) from the R546 package BSgenome.Hsapiens.UCSC.hg19 (TB, 2014). For this purpose, we searched every human 547 chromosome for poly-As of length 6 or longer and matched this information with the DSB map 548 genome coordinates provided by (Pratto et al., 2014). We then classify the poly-As with respect to 549 their location within the DSB into different regions, where poly-As can either be in a "hotspot" 550 (referring to the DSB-coordinates of (Pratto et al., 2014) with additional $500 \mathrm{bp}$ left and right), in 551 "hotspot flanking segments" or "outside hotspots". The hotspot flanking segments were split into 552 five adjacent sliding windows, each $1 \mathrm{~kb}$ left and right of the hotspot region. The first segment starts 553 at the left and right DSB hotspot thresholds ( $\pm 500 \mathrm{bp}$ ) and spans $1 \mathrm{~kb}$ left and right of these two 554 boundaries. We construct all further segments analogously using the new limits of adjacent regions 555 sequentially up to the fifth flanking region. The analysis corrects each region by the corresponding 556 total segment lengths (number of nucleotides).

557 Simons Genome Diversity Project (SGDP) analysis. The lobSTR reference sites called in from the 558 Simons Genome Diversity Project (SGDP) were downloaded from 559 http://strcat.teamerlich.org/download (Mallick et al., 2016, Willems et al., 2014). We restricted our 560 analysis to genotypes of the 300 individuals of Westeurasian descent (likely carriers of PRDM9 allele 561 A) and filtered out low quality calls as described in (Mallick et al., 2016). Since the default minimal 562 tract length of the called STRs was set to 11 nucleotides, no data for poly-As between 6-10 As were 563 available. Genome coordinates of perfect poly-A repeats were extracted, while imperfect poly-As 564 were removed. Repeats with more than 26 As were set to a length of 26. 
565 The heterozygosity for each site was calculated as $1-\sum_{i=1}^{n} p_{i}^{2}$ where $p_{i}$ is the frequency of the $i$ th 566 allele and $n$ is the number of different alleles at the locus. Further variables that we analyzed for each locus were the difference in length between the longest and shortest allele (allelic asymmetry),

568 length differences of alleles (steps in length), and the number of different alleles.

\section{Acknowledgements}

Open access funding was provided by the Austrian Science Fund (FWF). This work was also supported by the "Austrian Science Fund" (FWF) P7698000-B22 to IT-B. A.H was funded by a DOC Fellowship (24529) of the Austrian Academy of Sciences at the Institute of Biophysics Johannes Kepler University. B.A. was funded by a DOC Fellowship (23722) of the Austrian Academy of Sciences at the Institute of Biophysics Johannes Kepler University. We are grateful to Simon Myers and Nick Altemose for the correspondence about PRDM9 targets.

\section{Author contributions}

I.T.-B. conceived the research; A.H., B.A, and I.T.-B. designed the experiments; A.H. performed the experiments; A.J.B., P.H., G.P., A.H., B.A, A.F., T.E. and I.T.-B. contributed samples, new reagents/analytic tools/data; A.H., A.J.B., P.H., and G.P. analyzed the data; and A.H., A.J.B., P.H., G.P., B.A., and I.T.-B. wrote the paper. All authors read and approved the final manuscript.

\section{References}

ALTEMOSE, N., NOOR, N., BITOUN, E., TUMIAN, A., IMBEAULT, M., CHAPMAN, J. R., ARICESCU, A. R. \& MYERS, S. R. 2017. A map of human PRDM9 binding provides evidence for novel behaviors of PRDM9 and other zinc-finger proteins in meiosis. Elife, 6.

AMOS, W., KOSANOVIC, D. \& ERIKSSON, A. 2015. Inter-allelic interactions play a major role in microsatellite evolution. Proc Biol Sci, 282, 20152125.

ARBEITHUBER, B., BETANCOURT, A. J., EBNER, T. \& TIEMANN-BOEGE, I. 2015. Crossovers are associated with mutation and biased gene conversion at recombination hotspots. Proc Natl Acad Sci U S A, 112, 2109-14.

ARBEITHUBER, B., HEISSL, A. \& TIEMANN-BOEGE, I. 2017. Haplotyping of Heterozygous SNPs in Genomic DNA Using Long-Range PCR. Methods Mol Biol, 1551, 3-22.

ARNHEIM, N., CALABRESE, P. \& TIEMANN-BOEGE, I. 2007. Mammalian meiotic recombination hot spots. Annu Rev Genet, 41, 369-99.

ASSIS, R. \& KONDRASHOV, A. S. 2012. A strong deletion bias in nonallelic gene conversion. PLoS Genet, 8, e1002508.

BAGSHAW, A. T., PITT, J. P. \& GEMMELL, N. J. 2008. High frequency of microsatellites in S. cerevisiae meiotic recombination hotspots. BMC Genomics, 9, 49.

BAGSHAW, A. T. M. 2017. Functional mechanisms of microsatellite DNA in eukaryotic genomes. Genome Biology and Evolution, 9, 1-37.

BAKER, C. L., WALKER, M., KAJITA, S., PETKOV, P. M. \& PAIGEN, K. 2014. PRDM9 binding organizes hotspot nucleosomes and limits Holliday junction migration. Genome Res, 24, 724-32.

BAUDAT, F. \& DE MASSY, B. 2007. Cis- and trans-acting elements regulate the mouse Psmb9 meiotic recombination hotspot. PLoS Genet, 3, e100. 
608

609

610

611

612

613

614

615

616

617

618

619

620

621

622

623

624

625

626

627

628

629

630

631

632

633

634

635

636

637

638

639

640

641

642

643

644

645

646

647

648

649

650

651

652

653

654

655

656

657

658

659

BERG, I. L., NEUMANN, R., LAM, K. W., SARBAJNA, S., ODENTHAL-HESSE, L., MAY, C. A. \& JEFFREYS, A. J. 2010. PRDM9 variation strongly influences recombination hot-spot activity and meiotic instability in humans. Nature Genetics, 42, 859-63.

BILL, C. A., TAGHIAN, D. G., DURAN, W. A. \& NICKOLOFF, J. A. 2001. Repair bias of large loop mismatches during recombination in mammalian cells depends on loop length and structure. Mutat Res, 485, 255-65.

BISHOP, A. J. \& SCHIESTL, R. H. 2000. Homologous recombination as a mechanism for genome rearrangements: environmental and genetic effects. Hum Mol Genet, 9, 2427-334.

BOIS, P. \& JEFFREYS, A. J. 1999. Minisatellite instability and germline mutation. Cell Mol Life Sci, 55, 1636-48.

BOIS, P. R. 2007. A highly polymorphic meiotic recombination mouse hot spot exhibits incomplete repair. Mol Cell Biol, 27, 7053-62.

BOLAND, C. R. \& GOEL, A. 2010. Microsatellite instability in colorectal cancer. Gastroenterology, 138, 2073-2087 e3.

BRANDSTROM, M., BAGSHAW, A. T., GEMMELL, N. J. \& ELLEGREN, H. 2008. The relationship between microsatellite polymorphism and recombination hot spots in the human genome. Mol Biol Evol, 25, 2579-87.

BULMER, M. 1991. The selection-mutation-drift theory of synonymous codon usage. Genetics, 129, 897-907.

CHAKRABORTY, U. \& ALANI, E. 2016. Understanding how mismatch repair proteins participate in the repair/anti-recombination decision. FEMS Yeast Research, fow071-fow071.

CHOI, K., ZHAO, X., KELLY, K. A., VENN, O., HIGGINS, J. D., YELINA, N. E., HARDCASTLE, T. J., ZIOLKOWSKI, P. A., COPENHAVER, G. P., FRANKLIN, F. C., MCVEAN, G. \& HENDERSON, I. R. 2013. Arabidopsis meiotic crossover hot spots overlap with H2A.Z nucleosomes at gene promoters. Nat Genet, 45, 1327-36.

CHOI, K., ZHAO, X., TOCK, A. J., LAMBING, C., UNDERWOOD, C. J., HARDCASTLE, T. J., SERRA, H., KIM, J., CHO, H. S., KIM, J., ZIOLKOWSKI, P. A., YELINA, N. E., HWANG, I., MARTIENSSEN, R. A. \& HENDERSON, I. R. 2018. Nucleosomes and DNA methylation shape meiotic DSB frequency in Arabidopsis thaliana transposons and gene regulatory regions. Genome Res, 28, 532-546.

COLE, F., BAUDAT, F., GREY, C., KEENEY, S., DE MASSY, B. \& JASIN, M. 2014. Mouse tetrad analysis provides insights into recombination mechanisms and hotspot evolutionary dynamics. Nat Genet, 46, 1072-80.

COLE, F., KEENEY, S. \& JASIN, M. 2010. Comprehensive, fine-scale dissection of homologous recombination outcomes at a hot spot in mouse meiosis. Mol Cell, 39, 700-10.

CORRETTE-BENNETT, S. E., MOHLMAN, N. L., ROSADO, Z., MIRET, J. J., HESS, P. M., PARKER, B. O. \& LAHUE, R. S. 2001. Efficient repair of large DNA loops in Saccharomyces cerevisiae. Nucleic Acids Res, 29, 4134-43.

DE MASSY, B. 2013. Initiation of meiotic recombination: how and where? Conservation and specificities among eukaryotes. Annu Rev Genet, 47, 563-99.

DROUAUD, J., KHADEMIAN, H., GIRAUT, L., ZANNI, V., BELLALOU, S., HENDERSON, I. R., FALQUE, M. \& MEZARD, C. 2013. Contrasted patterns of crossover and non-crossover at Arabidopsis thaliana meiotic recombination hotspots. PLoS Genet, 9, e1003922.

DURET, L. \& GALTIER, N. 2009. Biased gene conversion and the evolution of mammalian genomic landscapes. Annu Rev Genomics Hum Genet, 10, 285-311.

ELLEGREN, H. 2004. Microsatellites: simple sequences with complex evolution. Nat Rev Genet, 5, 43545.

FIELD, Y., KAPLAN, N., FONDUFE-MITTENDORF, Y., MOORE, I. K., SHARON, E., LUBLING, Y., WIDOM, J. \& SEGAL, E. 2008. Distinct modes of regulation by chromatin encoded through nucleosome positioning signals. PLoS Comput Biol, 4, e1000216.

FUNGTAMMASAN, A., ANANDA, G., HILE, S. E., SU, M. S. W., SUN, C., HARRIS, R., MEDVEDEV, P., ECKERT, K. \& MAKOVA, K. D. 2015. Accurate typing of short tandem repeats from genomewide sequencing data and its applications. Genome Research, 125, 736-749. 
660

661

662

663

664

665

666

667

668

669

670

671

672

673

674

675

676

677

678

679

680

681

682

683

684

685

686

687

688

689

690

691

692

693

694

695

696

697

698

699

700

701

702

703

704

705

706

707

708

709

710

711

GENDREL, C. G., BOULET, A. \& DUTREIX, M. 2000. (CA/GT)(n) microsatellites affect homologous recombination during yeast meiosis. Genes and Development, 14, 1261-1268.

GLEMIN, S., ARNDT, P. F., MESSER, P. W., PETROV, D., GALTIER, N. \& DURET, L. 2015. Quantification of GC-biased gene conversion in the human genome. Genome Res, 25, 1215-28.

GOLDFARB, T. \& LICHTEN, M. 2010. Frequent and efficient use of the sister chromatid for DNA double-strand break repair during budding yeast meiosis. PLOS Biol, 8, e1000520.

GYMREK, M., WILLEMS, T., GUILMATRE, A., ZENG, H., MARKUS, B., GEORGIEV, S., DALY, M. J., PRICE, A. L., PRITCHARD, J. K., SHARP, A. J. \& ERLICH, Y. 2016. Abundant contribution of short tandem repeats to gene expression variation in humans. Nat Genet, 48, 22-9.

HALLDORSSON, B. V., HARDARSON, M. T., KEHR, B., STYRKARSDOTTIR, U., GYLFASON, A., THORLEIFSSON, G., ZINK, F., JONASDOTTIR, A., JONASDOTTIR, A., SULEM, P., MASSON, G., THORSTEINSDOTTIR, U., HELGASON, A., KONG, A., GUDBJARTSSON, D. F. \& STEFANSSON, K. 2016. The rate of meiotic gene conversion varies by sex and age. Nat Genet, 48, 1377-1384.

HEISSL, A., ARBEITHUBER, B. \& TIEMANN-BOEGE, I. 2017. High-Throughput Genotyping with TaqMan Allelic Discrimination and Allele-Specific Genotyping Assays. Methods Mol Biol, 1492, 29-57.

HORTON, M. W., HANCOCK, A. M., HUANG, Y. S., TOOMAJIAN, C., ATWELL, S., AUTON, A., MULIYATI, N. W., PLATT, A., SPERONE, F. G., VILHJALMSSON, B. J., NORDBORG, M., BOREVITZ, J. O. \& BERGELSON, J. 2012. Genome-wide patterns of genetic variation in worldwide Arabidopsis thaliana accessions from the RegMap panel. Nat Genet, 44, 212-6.

HUI, J., HUNG, L. H., HEINER, M., SCHREINER, S., NEUMULLER, N., REITHER, G., HAAS, S. A. \& BINDEREIF, A. 2005. Intronic CA-repeat and CA-rich elements: a new class of regulators of mammalian alternative splicing. EMBO J, 24, 1988-98.

INTERNATIONAL HAPMAP, C., FRAZER, K. A., BALLINGER, D. G., COX, D. R., HINDS, D. A., STUVE, L. L., GIBBS, R. A., BELMONT, J. W., BOUDREAU, A., HARDENBOL, P., LEAL, S. M., PASTERNAK, S., WHEELER, D. A., WILLIS, T. D., YU, F., YANG, H., ZENG, C., GAO, Y., HU, H., HU, W., LI, C., LIN, W., LIU, S., PAN, H., TANG, X., WANG, J., WANG, W., YU, J., ZHANG, B., ZHANG, Q., ZHAO, H., ZHAO, H., ZHOU, J., GABRIEL, S. B., BARRY, R., BLUMENSTIEL, B., CAMARGO, A., DEFELICE, M., FAGGART, M., GOYETTE, M., GUPTA, S., MOORE, J., NGUYEN, H., ONOFRIO, R. C., PARKIN, M., ROY, J., STAHL, E., WINCHESTER, E., ZIAUGRA, L., ALTSHULER, D., SHEN, Y., YAO, Z., HUANG, W., CHU, X., HE, Y., JIN, L., LIU, Y., SHEN, Y., SUN, W., WANG, H., WANG, Y., WANG, Y., XIONG, X., XU, L., WAYE, M. M., TSUI, S. K., XUE, H., WONG, J. T., GALVER, L. M., FAN, J. B., GUNDERSON, K., MURRAY, S. S., OLIPHANT, A. R., CHEE, M. S., MONTPETIT, A., CHAGNON, F., FERRETTI, V., LEBOEUF, M., OLIVIER, J. F., PHILLIPS, M. S., ROUMY, S., SALLEE, C., VERNER, A., HUDSON, T. J., KWOK, P. Y., CAI, D., KOBOLDT, D. C., MILLER, R. D., PAWLIKOWSKA, L., TAILLON-MILLER, P., XIAO, M., TSUI, L. C., MAK, W., SONG, Y. Q., TAM, P. K., NAKAMURA, Y., KAWAGUCHI, T., KITAMOTO, T., MORIZONO, T., NAGASHIMA, A., et al. 2007. A second generation human haplotype map of over 3.1 million SNPs. Nature, 449, 851-61.

JANKOWSKI, C., NASAR, F. \& NAG, D. K. 2000. Meiotic instability of CAG repeat tracts occurs by double-strand break repair in yeast. Proc Natl Acad Sci U S A, 97, 2134-9.

JEFFREYS, A. J., KAUPPI, L. \& NEUMANN, R. 2001. Intensely punctate meiotic recombination in the class II region of the major histocompatibility complex. Nat Genet, 29, 217-22.

JEFFREYS, A. J. \& MAY, C. A. 2004. Intense and highly localized gene conversion activity in human meiotic crossover hot spots. Nat Genet, 36, 151-6.

JEFFREYS, A. J., NEIL, D. L. \& NEUMANN, R. 1998. Repeat instability at human minisatellites arising from meiotic recombination. $E M B O J, 17,4147-57$.

JEFFREYS, A. J. \& NEUMANN, R. 2002. Reciprocal crossover asymmetry and meiotic drive in a human recombination hot spot. Nat Genet, 31, 267-71.

JEFFREYS, A. J. \& NEUMANN, R. 2005. Factors influencing recombination frequency and distribution in a human meiotic crossover hotspot. Hum Mol Genet, 14, $2277-87$.

JENSEN, L. E., JAUERT, P. A. \& KIRKPATRICK, D. T. 2005. The large loop repair and mismatch repair pathways of Saccharomyces cerevisiae act on distinct substrates during meiosis. Genetics, $170,1033-43$. 
JENSEN-SEAMAN, M. I., FUREY, T. S., PAYSEUR, B. A., LU, Y., ROSKIN, K. M., CHEN, C. F., THOMAS, M. A., HAUSSLER, D. \& JACOB, H. J. 2004. Comparative recombination rates in the rat, mouse, and human genomes. Genome Res, 14, 528-38.

JESSOP, L. \& LICHTEN, M. 2008. Mus81/Mms4 endonuclease and Sgs1 helicase collaborate to ensure proper recombination intermediate metabolism during meiosis. Mol Cell, 31, 313-23.

JIRICNY, J. 2006. The multifaceted mismatch-repair system. Nat Rev Mol Cell Biol, 7, 335-46.

KIRKPATRICK, D. T. \& PETES, T. D. 1997. Repair of DNA loops involves DNA-mismatch and nucleotideexcision repair proteins. Nature, 387, 929-31.

KIRKPATRICK, D. T., WANG, Y. H., DOMINSKA, M., GRIFFITH, J. D. \& PETES, T. D. 1999. Control of meiotic recombination and gene expression in yeast by a simple repetitive DNA sequence that excludes nucleosomes. Mol Cell Biol, 19, 7661-71.

KONG, A., GUDBJARTSSON, D. F., SAINZ, J., JONSDOTTIR, G. M., GUDJONSSON, S. A., RICHARDSSON, B., SIGURDARDOTTIR, S., BARNARD, J., HALLBECK, B., MASSON, G., SHLIEN, A., PALSSON, S. T., FRIGGE, M. L., THORGEIRSSON, T. E., GULCHER, J. R. \& STEFANSSON, K. 2002. A highresolution recombination map of the human genome. Nat Genet, 31, 241-7.

LAM, I. \& KEENEY, S. 2014. Mechanism and regulation of meiotic recombination initiation. Cold Spring Harb Perspect Biol, 7, a016634.

LANDER, E. S., LINTON, L. M., BIRREN, B., NUSBAUM, C., ZODY, M. C., BALDWIN, J., DEVON, K., DEWAR, K., DOYLE, M., FITZHUGH, W., FUNKE, R., GAGE, D., HARRIS, K., HEAFORD, A., HOWLAND, J., KANN, L., LEHOCZKY, J., LEVINE, R., MCEWAN, P., MCKERNAN, K., MELDRIM, J., MESIROV, J. P., MIRANDA, C., MORRIS, W., NAYLOR, J., RAYMOND, C., ROSETTI, M., SANTOS, R., SHERIDAN, A., SOUGNEZ, C., STANGE-THOMANN, Y., STOJANOVIC, N., SUBRAMANIAN, A., WYMAN, D., ROGERS, J., SULSTON, J., AINSCOUGH, R., BECK, S., BENTLEY, D., BURTON, J., CLEE, C., CARTER, N., COULSON, A., DEADMAN, R., DELOUKAS, P., DUNHAM, A., DUNHAM, I., DURBIN, R., FRENCH, L., GRAFHAM, D., GREGORY, S., HUBBARD, T., HUMPHRAY, S., HUNT, A., JONES, M., LLOYD, C., MCMURRAY, A., MATTHEWS, L., MERCER, S., MILNE, S., MULLIKIN, J. C., MUNGALL, A., PLUMB, R., ROSS, M., SHOWNKEEN, R., SIMS, S., WATERSTON, R. H., WILSON, R. K., HILLIER, L. W., MCPHERSON, J. D., MARRA, M. A., MARDIS, E. R., FULTON, L. A., CHINWALLA, A. T., PEPIN, K. H., GISH, W. R., CHISSOE, S. L., WENDL, M. C., DELEHAUNTY, K. D., MINER, T. L., DELEHAUNTY, A., KRAMER, J. B., COOK, L. L., FULTON, R. S., JOHNSON, D. L., MINX, P. J., CLIFTON, S. W., HAWKINS, T., BRANSCOMB, E., PREDKI, P., RICHARDSON, P., WENNING, S., SLEZAK, T., DOGGETT, N., CHENG, J. F., OLSEN, A., LUCAS, S., ELKIN, C., UBERBACHER, E., FRAZIER, M., et al. 2001. Initial sequencing and analysis of the human genome. Nature, 409, 860-921.

LANGE, J., YAMADA, S., TISCHFIELD, S. E., PAN, J., KIM, S., ZHU, X., SOCCI, N. D., JASIN, M. \& KEENEY, S. 2016. The Landscape of Mouse Meiotic Double-Strand Break Formation, Processing, and Repair. Cell, 167, 695-708 e16.

LASSALLE, F., PERIAN, S., BATAILLON, T., NESME, X., DURET, L. \& DAUBIN, V. 2015. GC-Content evolution in bacterial genomes: the biased gene conversion hypothesis expands. PLoS Genet, 11, e1004941.

LESECQUE, Y., MOUCHIROUD, D. \& DURET, L. 2013. GC-biased gene conversion in yeast is specifically associated with crossovers: molecular mechanisms and evolutionary significance. Mol Biol Evol, 30, 1409-19.

LEUSHKIN, E. V. \& BAZYKIN, G. A. 2013. Short indels are subject to insertion-biased gene conversion. Evolution, 67, 2604-13.

MALLICK, S., LI, H., LIPSON, M., MATHIESON, I., GYMREK, M., RACIMO, F., ZHAO, M., CHENNAGIRI, N., NORDENFELT, S., TANDON, A., SKOGLUND, P., LAZARIDIS, I., SANKARARAMAN, S., FU, Q., ROHLAND, N., RENAUD, G., ERLICH, Y., WILLEMS, T., GALLO, C., SPENCE, J. P., SONG, Y. S., POLETTI, G., BALLOUX, F., VAN DRIEM, G., DE KNIJFF, P., ROMERO, I. G., JHA, A. R., BEHAR, D. M., BRAVI, C. M., CAPELLI, C., HERVIG, T., MORENO-ESTRADA, A., POSUKH, O. L., BALANOVSKA, E., BALANOVSKY, O., KARACHANAK-YANKOVA, S., SAHAKYAN, H., TONCHEVA, D., YEPISKOPOSYAN, L., TYLER-SMITH, C., XUE, Y., ABDULLAH, M. S., RUIZ-LINARES, A., BEALL, 
C. M., DI RIENZO, A., JEONG, C., STARIKOVSKAYA, E. B., METSPALU, E., PARIK, J., VILLEMS, R., HENN, B. M., HODOGLUGIL, U., MAHLEY, R., SAJANTILA, A., STAMATOYANNOPOULOS, G., WEE, J. T. S., KHUSAINOVA, R., KHUSNUTDINOVA, E., LITVINOV, S., AYODO, G., COMAS, D., HAMMER, M. F., KIVISILD, T., KLITZ, W., WINKLER, C. A., LABUDA, D., BAMSHAD, M., JORDE, L. B., TISHKOFF, S. A., WATKINS, W. S., METSPALU, M., DRYOMOV, S., SUKERNIK, R., SINGH, L., THANGARAJ, K., PAÄBO, S., KELSO, J., PATTERSON, N. \& REICH, D. 2016. The Simons Genome Diversity Project: 300 genomes from 142 diverse populations. Nature, 538, 201-206. MANHART, C. M. \& ALANI, E. 2016. Roles for mismatch repair family proteins in promoting meiotic crossing over. DNA Repair, 38, 84-93.

MCCULLOCH, S. D., GU, L. \& LI, G. M. 2003a. Bi-directional processing of DNA loops by mismatch repair-dependent and -independent pathways in human cells. J Biol Chem, 278, 3891-6.

MCCULLOCH, S. D., GU, L. \& LI, G. M. 2003b. Nick-dependent and -independent processing of large DNA loops in human cells. $J$ Biol Chem, 278, 50803-9.

MYERS, S., BOTTOLO, L., FREEMAN, C., MCVEAN, G. \& DONNELLY, P. 2005. A fine-scale map of recombination rates and hotspots across the human genome. Science, 310, 321-4.

MYERS, S., BOWDEN, R., TUMIAN, A., BONTROP, R. E., FREEMAN, C., MACFIE, T. S., MCVEAN, G. \& DONNELLY, P. 2010. Drive against hotspot motifs in primates implicates the PRDM9 gene in meiotic recombination. Science, 327, 876-9.

MYERS, S., FREEMAN, C., AUTON, A., DONNELLY, P. \& MCVEAN, G. 2008. A common sequence motif associated with recombination hot spots and genome instability in humans. Nat Genet.

NAG, D. K., SURI, M. \& STENSON, E. K. 2004. Both CAG repeats and inverted DNA repeats stimulate spontaneous unequal sister-chromatid exchange in Saccharomyces cerevisiae. Nucleic Acids Res, 32, 5677-84.

NAGYLAKI, T. 1983. Evolution of a finite population under gene conversion. Proc Natl Acad Sci U S A, 80, 6278-81.

NELSON, H. C., FINCH, J. T., LUISI, B. F. \& KLUG, A. 1987. The structure of an oligo(dA). oligo(dT) tract and its biological implications. Nature, 330, 221-6.

ODENTHAL-HESSE, L., BERG, I. L., VESELIS, A., JEFFREYS, A. J. \& MAY, C. A. 2014. Transmission distortion affecting human noncrossover but not crossover recombination: a hidden source of meiotic drive. PLoS Genet, 10, e1004106.

OH, S. D., LAO, J. P., HWANG, P. Y., TAYLOR, A. F., SMITH, G. R. \& HUNTER, N. 2007. BLM ortholog, Sgs1, prevents aberrant crossing-over by suppressing formation of multichromatid joint molecules. Cell, 130, 259-72.

OHTA, K., SHIBATA, T. \& NICOLAS, A. 1994. Changes in chromatin structure at recombination initiation sites during yeast meiosis. EMBOJ, 13, 5754-63.

OMETTO, L., STEPHAN, W. \& DE LORENZO, D. 2005. Insertion/deletion and nucleotide polymorphism data reveal constraints in Drosophila melanogaster introns and intergenic regions. Genetics, 169, 1521-7.

PAIGEN, K. \& PETKOV, P. 2010. Mammalian recombination hot spots: properties, control and evolution. Nature reviews. Genetics, 11, 221-33.

PAIGEN, K. \& PETKOV, P. M. 2018. PRDM9 and Its Role in Genetic Recombination. Trends Genet, 34, 291-300.

PAIGEN, K., SZATKIEWICZ, J. P., SAWYER, K., LEAHY, N., PARVANOV, E. D., NG, S. H., GRABER, J. H., BROMAN, K. W. \& PETKOV, P. M. 2008. The recombinational anatomy of a mouse chromosome. PLoS Genet, 4, e1000119.

PATHAK, R. U., MAMILLAPALLI, A., RANGARAJ, N., KUMAR, R. P., VASANTHI, D., MISHRA, K. \& MISHRA, R. K. 2013. AAGAG repeat RNA is an essential component of nuclear matrix in Drosophila. RNA Biol, 10, 564-71.

PAYSEUR, B. A. \& NACHMAN, M. W. 2000. Microsatellite variation and recombination rate in the human genome. Genetics, 156, 1285-98.

PEARSON, C. E., NICHOL EDAMURA, K. \& CLEARY, J. D. 2005. Repeat instability: mechanisms of dynamic mutations. Nature Reviews Genetics, 6, 729-742. 
POLLEYS, E. J., HOUSE, N. C. M. \& FREUDENREICH, C. H. 2017. Role of recombination and replication fork restart in repeat instability. DNA Repair (Amst), 56, 156-165.

POLYZOS, A. A. \& MCMURRAY, C. T. 2017. Close encounters: Moving along bumps, breaks, and bubbles on expanded trinucleotide tracts. DNA Repair, 56, 144-155.

POWERS, N. R., PARVANOV, E. D., BAKER, C. L., WALKER, M., PETKOV, P. M. \& PAIGEN, K. 2016. The Meiotic Recombination Activator PRDM9 Trimethylates Both H3K36 and H3K4 at Recombination Hotspots In Vivo. PLoS Genet, 12, e1006146.

PRATTO, F., BRICK, K., KHIL, P., SMAGULOVA, F., PETUKHOVA, G. V. \& CAMERINI-OTERO, R. D. 2014. DNA recombination. Recombination initiation maps of individual human genomes. Science, $346,1256442$.

PRESGRAVES, D. C. 2006. Intron length evolution in Drosophila. Mol Biol Evol, 23, 2203-13.

RICHARD, G.-F., KERREST, A. \& DUJON, B. 2008. Comparative genomics and molecular dynamics of DNA repeats in eukaryotes. Microbiology and molecular biology reviews : MMBR, 72, 686727.

ROCCO, V. \& NICOLAS, A. 1996. Sensing of DNA non-homology lowers the initiation of meiotic recombination in yeast. Genes Cells, 1, 645-61.

SCHULTES, N. P. \& SZOSTAK, J. W. 1991. A poly(dA.dT) tract is a component of the recombination initiation site at the ARG4 locus in Saccharomyces cerevisiae. Mol Cell Biol, 11, 322-8.

SCHWACHA, A. \& KLECKNER, N. 1994. Identification of joint molecules that form frequently between homologs but rarely between sister chromatids during yeast meiosis. Cell, 76, 51-63.

SCHWACHA, A. \& KLECKNER, N. 1997. Interhomolog bias during meiotic recombination: meiotic functions promote a highly differentiated interhomolog-only pathway. Cell, 90, 1123-35.

SEGAL, E. \& WIDOM, J. 2009. Poly(dA:dT) tracts: major determinants of nucleosome organization. Curr Opin Struct Biol, 19, 65-71.

SHERRY, S. T., WARD, M. H., KHOLODOV, M., BAKER, J., PHAN, L., SMIGIELSKI, E. M. \& SIROTKIN, K. 2001. dbSNP: the NCBI database of genetic variation. Nucleic Acids Res, 29, 308-11.

SHOKAL, U. \& SHARMA, P. C. 2012. Implication of microsatellite instability in human gastric cancers. Indian J Med Res, 135, 599-613.

SIA, E. A., JINKS-ROBERTSON, S. \& PETES, T. D. 1997. Genetic control of microsatellite stability. Mutat Res, 383, 61-70.

SNYDER, T. M., TSE, B. N. \& LIU, D. R. 2008. Effects of template sequence and secondary structure on DNA-templated reactivity. J Am Chem Soc, 130, 1392-401.

SOMMER, D., STITH, C. M., BURGERS, P. M. \& LAHUE, R. S. 2008. Partial reconstitution of DNA large loop repair with purified proteins from Saccharomyces cerevisiae. Nucleic Acids Res, 36, 4699-707.

SPIES, M. \& FISHEL, R. 2015. Mismatch Repair during Homologous and Homeologous Recombination. CSH Perspectives in Biology, 1-22.

SUN, J. X., HELGASON, A., MASSON, G., EBENESERSDOTTIR, S. S., LI, H., MALLICK, S., GNERRE, S., PATTERSON, N., KONG, A., REICH, D. \& STEFANSSON, K. 2012. A direct characterization of human mutation based on microsatellites. Nat Genet, 44, 1161-5.

TB, T. 2014. BSgenome.Hsapiens.UCSC.hg19: Full genome sequences for Homo sapiens (UCSC version hg19). R package version 1.4.0.

TIAN, D., WANG, Q., ZHANG, P., ARAKI, H., YANG, S., KREITMAN, M., NAGYLAKI, T., HUDSON, R., BERGELSON, J. \& CHEN, J. Q. 2008. Single-nucleotide mutation rate increases close to insertions/deletions in eukaryotes. Nature, 455, 105-8.

TIEMANN-BOEGE, I., CALABRESE, P., COCHRAN, D. M., SOKOL, R. \& ARNHEIM, N. 2006. Highresolution recombination patterns in a region of human chromosome 21 measured by sperm typing. PLoS Genet, 2, e70.

TIEMANN-BOEGE, I., SCHWARZ, T., STRIEDNER, Y. \& HEISSL, A. 2017. The consequences of sequence erosion in the evolution of recombination hotspots. Philos Trans R Soc Lond B Biol Sci, 372. 
TRECO, D. \& ARNHEIM, N. 1986. The evolutionarily conserved repetitive sequence d(TG.AC)n promotes reciprocal exchange and generates unusual recombinant tetrads during yeast meiosis. Mol Cell Biol, 6, 3934-47.

TSAPONINA, O. \& HABER, J. E. 2014. Frequent Interchromosomal Template Switches during Gene Conversion in S. cerevisiae. Mol Cell, 55, 615-25.

WANG, G. \& VASQUEZ, K. M. 2006. Non-B DNA structure-induced genetic instability. Mutat Res, 598, 103-19.

WEBB, A. J., BERG, I. L. \& JEFFREYS, A. 2008. Sperm cross-over activity in regions of the human genome showing extreme breakdown of marker association. Proc Natl Acad Sci U SA, 105, 10471-6.

WIJNKER, E., VELIKKAKAM JAMES, G., DING, J., BECKER, F., KLASEN, J. R., RAWAT, V., ROWAN, B. A., DE JONG, D. F., DE SNOO, C. B., ZAPATA, L., HUETTEL, B., DE JONG, H., OSSOWSKI, S., WEIGEL, D., KOORNNEEF, M., KEURENTJES, J. J. \& SCHNEEBERGER, K. 2013. The genomic landscape of meiotic crossovers and gene conversions in Arabidopsis thaliana. eLife, 2, e01426.

WILLEMS, T., GYMREK, M., HIGHNAM, G., GENOMES PROJECT, C., MITTELMAN, D. \& ERLICH, Y. 2014. The landscape of human STR variation. Genome Res, 24, 1894-904.

WILLIAMS, A. L., GENOVESE, G., DYER, T., ALTEMOSE, N., TRUAX, K., JUN, G., PATTERSON, N., MYERS, S. R., CURRAN, J. E., DUGGIRALA, R., BLANGERO, J., REICH, D., PRZEWORSKI, M. \& CONSORTIUM, T. D. G. 2015. Non-crossover gene conversions show strong GC bias and unexpected clustering in humans. Elife, 4.

WU, Z. K., GETUN, I. V. \& BOIS, P. R. 2010. Anatomy of mouse recombination hot spots. Nucleic Acids Res, 38, 2346-54.

XU, L., AJIMURA, M., PADMORE, R., KLEIN, C. \& KLECKNER, N. 1995. NDT80, a meiosis-specific gene required for exit from pachytene in Saccharomyces cerevisiae. Mol Cell Biol, 15, 6572-81.

ZAVODNA, M., BAGSHAW, A., BRAUNING, R. \& GEMMELL, N. J. 2018. The effects of transcription and recombination on mutational dynamics of short tandem repeats. Nucleic Acids Res, 46, 13211330 . 
bioRxiv preprint doi: https://doi.org/10.1101/431841; this version posted October 3, 2018. The copyright holder for this preprint (which was not certified by peer review) is the author/funder, who has granted bioRxiv a license to display the preprint in perpetuity. It is made available under aCC-BY-NC-ND 4.0 International license.

\begin{tabular}{|c|c|c|c|c|c|c|c|}
\hline & & $\begin{array}{c}\text { Rate Ratio } \\
\text { (strong:weak) }\end{array}$ & p-value & FxR & c & $\begin{array}{l}\text { Fx total } \\
\text { (HSII) }\end{array}$ & b \\
\hline \multicolumn{8}{|l|}{$g B G C$} \\
\hline \multirow{3}{*}{$\mathrm{CO}$} & $\mathrm{Ht}+\mathrm{Ho}$ & $1.27(1.17-1.38)$ & $<1 \mathrm{e}-4$ & $53.0 \%$ & $2.5 \mathrm{E}-03$ & $50.013 \%$ & $2.68 \mathrm{E}-04$ \\
\hline & $\mathrm{Ht}$ & $1.10(0.98-1.23)$ & 0.13 & $51.2 \%$ & $2.1 \mathrm{E}-03$ & $50.004 \%$ & $8.76 \mathrm{E}-05$ \\
\hline & $\mathrm{Ho}$ & $1.50(1.33-1.69)$ & $<1 \mathrm{e}-4$ & $55.1 \%$ & $3.6 \mathrm{E}-03$ & $50.031 \%$ & $6.28 \mathrm{E}-04$ \\
\hline \multirow{3}{*}{ NCO } & $\mathrm{Ht}+\mathrm{Ho}$ & $0.93(0.73-1.19)$ & 0.58 & $49.0 \%$ & 7.1E-04 & $49.999 \%$ & $-1.41 \mathrm{E}-05$ \\
\hline & $\mathrm{Ht}$ & $0.61(0.42-0.86)$ & $<1 \mathrm{e}-2$ & $43.9 \%$ & $1.1 \mathrm{E}-03$ & $49.993 \%$ & $-1.35 E-04$ \\
\hline & Ho & $1.54(1.06-2.26)$ & 0.02 & $55.4 \%$ & $5.0 \mathrm{E}-04$ & $50.003 \%$ & $5.38 \mathrm{E}-05$ \\
\hline \multicolumn{8}{|l|}{$i B G C$} \\
\hline \multirow{6}{*}{$\mathrm{CO}$} & Ht $6 / 7+9 / 19$, Ho $6 / 7$ & $1.17(1.12-1.23)$ & $<1 \mathrm{e}-4$ & $52.0 \%$ & $2.1 \mathrm{E}-03$ & $50.004 \%$ & $8.27 \mathrm{E}-05$ \\
\hline & $\mathrm{Ht}+\mathrm{Ho} 6 / 7$ & $1.91(1.60-2.28)$ & $<1 \mathrm{e}-4$ & $58.0 \%$ & $3.1 \mathrm{E}-03$ & $50.025 \%$ & 4.97E-04 \\
\hline & $\mathrm{Ht} 6 / 7+9 / 19$ & $1.17(1.12-1.22)$ & $<1 \mathrm{e}-4$ & $52.0 \%$ & $2.9 \mathrm{E}-03$ & $50.006 \%$ & $1.14 \mathrm{E}-4$ \\
\hline & Ht 9/19 & $1.02(1.00-1.04)$ & 0.07 & $50.2 \%$ & $2.1 \mathrm{E}-03$ & $50.001 \%$ & $1.05 \mathrm{E}-05$ \\
\hline & $\mathrm{Ht} 6 / 7$ & $1.95(1.62-2.34)$ & $<1 \mathrm{e}-4$ & $58.3 \%$ & $2.9 \mathrm{E}-03$ & $50.024 \%$ & $4.80 \mathrm{E}-04$ \\
\hline & Ho $6 / 7$ & $1.56(0.80-3.03)$ & 0.25 & $57.2 \%$ & $3.6 \mathrm{E}-03$ & $50.026 \%$ & $5.18 \mathrm{E}-04$ \\
\hline \multirow{6}{*}{$\mathrm{NCO}$} & Ht $6 / 7+9 / 19$, Ho $6 / 7$ & $0.59(0.32-1.05)$ & 0.08 & $43.4 \%$ & $1.4 \mathrm{E}-03$ & $49.991 \%$ & $-1.87 \mathrm{E}-04$ \\
\hline & $\mathrm{Ht}+\mathrm{Ho} 6 / 7$ & $1.54(0.73-3.37)$ & 0.30 & $55.4 \%$ & 7.2E-04 & $50.004 \%$ & $7.36 \mathrm{E}-05$ \\
\hline & $\mathrm{Ht} 6 / 7+9 / 19$ & $0.25(0.08-0.63)$ & 0.001 & $33.3 \%$ & $1.3 \mathrm{E}-04$ & $49.978 \%$ & 4.33E-04 \\
\hline & $\mathrm{Ht} 6 / 7$ & $2.0(0.4-12.3)$ & 0.51 & $58.6 \%$ & $1.3 \mathrm{E}-03$ & $50.011 \%$ & $2.23 \mathrm{E}-04$ \\
\hline & Ht 9/19 & $0.0(0.00-0.19)$ & $<1 \mathrm{e}-6$ & $0.0 \%$ & $1.1 \mathrm{E}-03$ & $49.945 \%$ & $-1.10 \mathrm{E}-03$ \\
\hline & Ho $6 / 7$ & $1.4(0.58-3.52)$ & 0.54 & $54.2 \%$ & $5.0 \mathrm{E}-04$ & $50.002 \%$ & 4.20E-05 \\
\hline
\end{tabular}

Table 1. Estimated gBGC and $\mathrm{BBGC}$ for $\mathrm{CO}$ and $\mathrm{NCO}$ grouped into all donors $(\mathrm{Ht}+\mathrm{Ho}), \mathrm{Ht}$, or $\mathrm{Ho}$

$R R$ is the rate-ratio of strong to weak alleles for $g B G C$ or long vs. short alleles for $B B G C ; p$ is the significance of the RR; FXR is the fraction of recombinant with a biased transmission estimated as VWRR / (1+ VWRR), $c$ is the crossover frequency estimated from the data (SM-Table S2); Fx total is the proportion of NR + proportion of biased $R ; b$ is the selection coefficient estimated as ( $2^{*} F x$ total) -1 

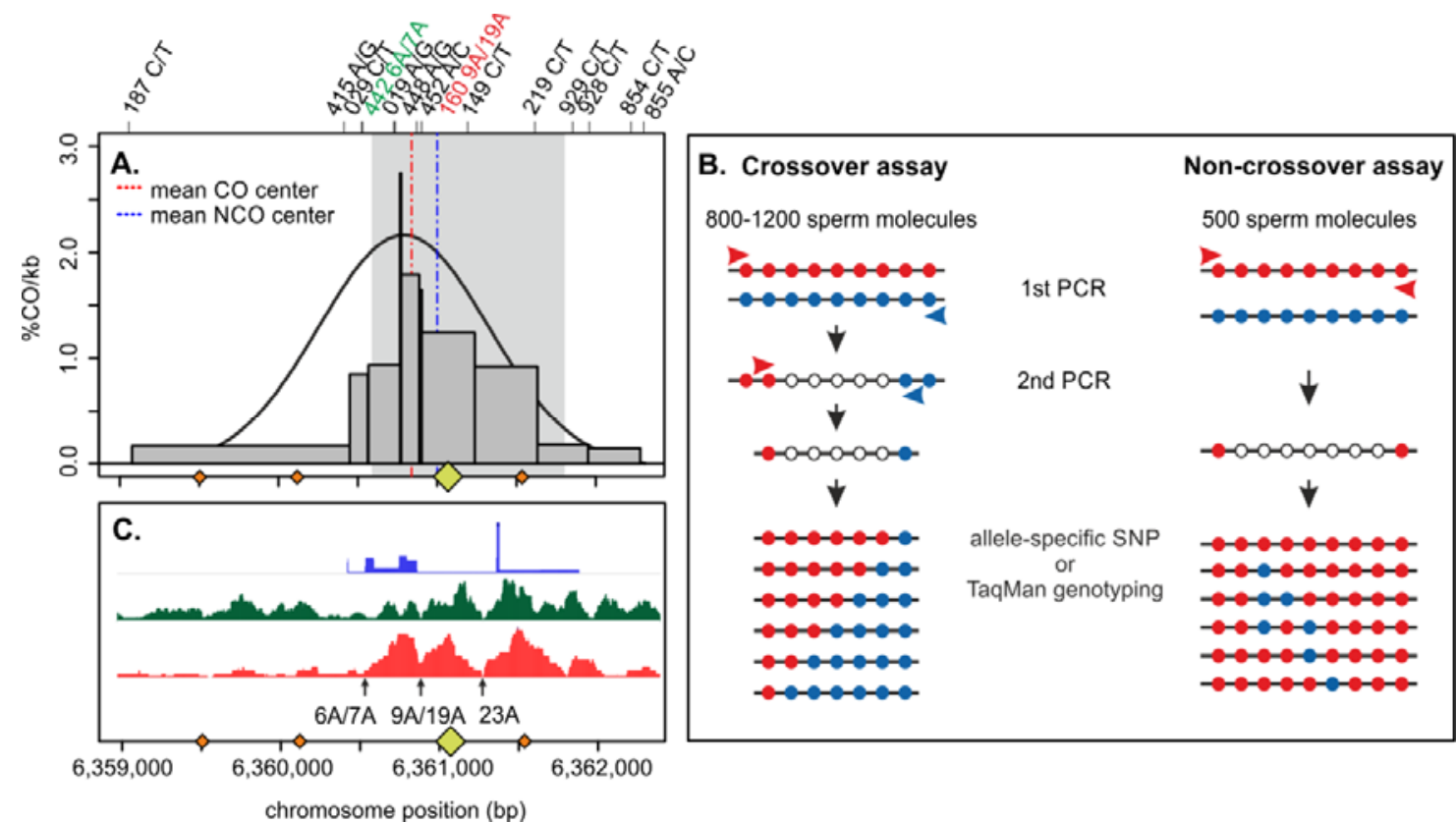

Figure 1. Features and analysis of HSII. A. Distribution of crossover (CO) breakpoints (grey bars) measured with pooled-sperm typing in eight different donors. The mean $\mathrm{CO}$ and $\mathrm{NCO}$ centers (dashed lines) were estimated at chr16:6,360,770 \pm 9 bp and 6,360,860 \pm 15 bp (GRCh37/hg19), respectively (SM-Fig. S1-6 and SMTable S2). Orange rhomboids on the $x$-axis represent the $\mathrm{PRDM}^{A}$ binding motif with up to one mismatch (CCnCCnTnnCCnC; where $n$ reflects any base A,C,T,G with the same likelihood) (Myers et al., 2008). The larger yellow rhomboid at position chr16:6,361,057-6,361,088 is likely the most active motif (verified to bind PRDM9 in transfected cells with a significant FIMO score; personal communication and (Altemose et al., 2017). The grey shaded area represents the DSB region measured in spermatocytes (Pratto et al., 2014) B. Graphical representation of the pooled-sperm typing assay to collect COs and NCOs. Approximately 800-1,200 or 500 sperm molecules were aliquoted per reaction for collecting COs or NCOs, respectively. COs were amplified with allele-specific primers with a perfect match at the $3^{\prime}$ end to the allele of the recombinant phase (red and blue arrows). The two nested PCRs produced mainly crossover amplicons. The NCO assay used allele-specific primers to amplify only one of the parental homologues. The phase switch of internal alleles representing the NCO was assessed by allele-specific PCRs targeting one SNP at a time. C. Additional features of HSII as described in (Altemose et al., 2017). The first lane represents the historical recombination map inferred with LDHat (International HapMap et al., 2007) in dark blue, the second lane is the measured H3K4me3 in human spermatocytes of PRDM9 ${ }^{A}$ carriers (Pratto et al., 2014) in green, and the third lane represents the H3K4me3 sites measured in HEK293T cells transfected with PRDM9 ${ }^{A}$ in bright red (Altemose et al., 2017). The black arrows denote the location of the three poly-A sites within HSII. 
A.

9A/19A donors

19A/19A donors

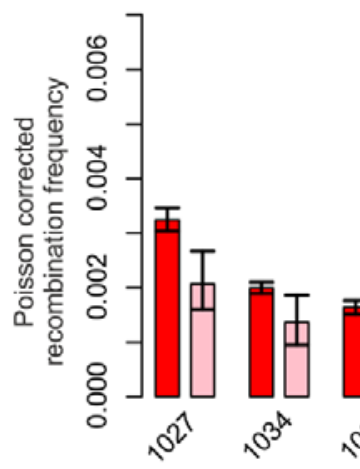

Figure 2. Recombination frequencies of $\mathrm{CO}$ and NCO measured in HSII. A. CO and NCO frequencies compared by individual donors and donor groups. $\mathrm{CO}$ frequencies (red) of 9A/19A heterozygous $(\mathrm{Ht})$ donors are lower than $\mathrm{CO}$ frequencies of homozygous (Ho) donors (dark blue). This trend is reversed for NCOs, in which NCOs are more frequent in $\mathrm{Ht}$ (light red) than in $\mathrm{Ho}$ (light blue) donors. Error bars denote confidence intervals calculated by an exact two-sided Poisson test. B. Average $\mathrm{CO}$ and $\mathrm{NCO}$ frequency in $\mathrm{Ht}$ and $\mathrm{Ho}$ donor groups. 
bioRxiv preprint doi: https://doi.org/10.1101/431841; this version posted October 3, 2018. The copyright holder for this preprint (which was not certified by peer review) is the author/funder, who has granted bioRxiv a license to display the preprint in perpetuity. It is made available under aCC-BY-NC-ND 4.0 International license.

Donor 1034 - 9A/19A Ht

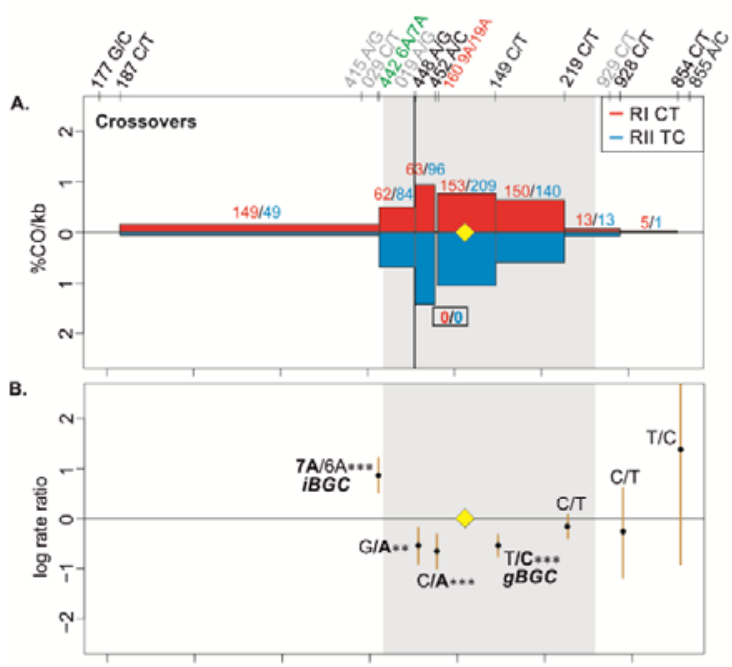

c.

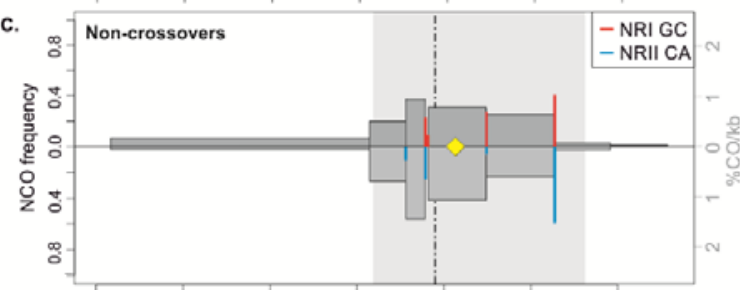

D.

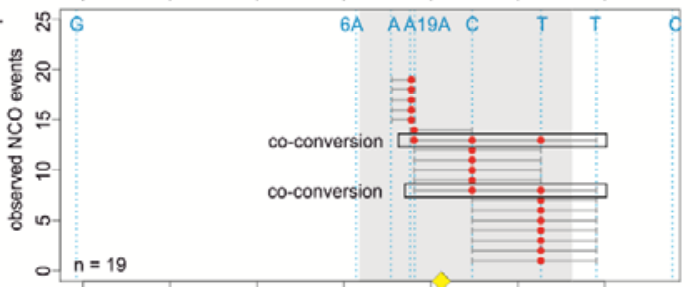

E.

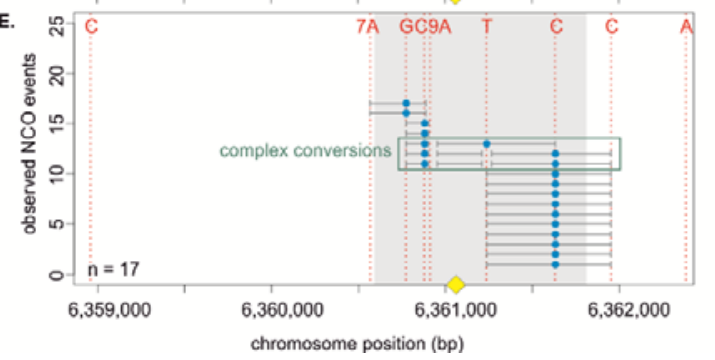

Donor 1227 - 19A/19A Ho
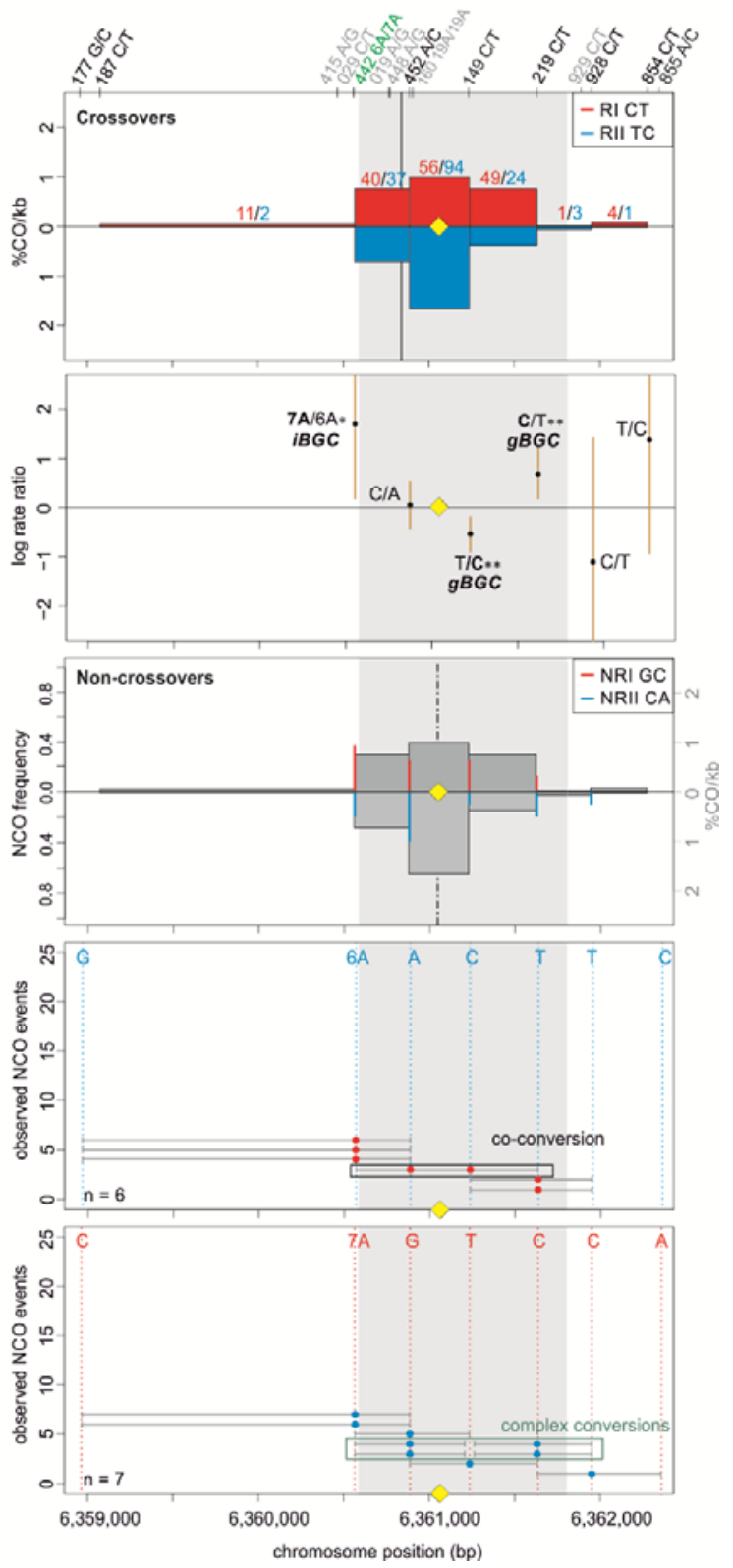

Figure 3. CO and NCO transmission of 9A/19A Ht donor (left) and 19A/19A Ho donor (right). A. CO transmission between reciprocals $\mathrm{CO}$ breakpoint distributions of both reciprocal products based on $n=1,313$ and 344 collected CO products for donor 1034 and donor 1227, respectively (also see SM-Table S2). Note that numbers on top of the breakpoint sites are normalized to represent equal numbers of collected reciprocals. The average $\mathrm{CO}$ centers estimated either for the $\mathrm{Ht}$ or the Ho group is denoted by the black vertical lines, the grey area denotes the DSB zone (Pratto et al., 2014), and the yellow rhomboid represents the PRDM9 binding site. Note the absence of breakpoints at the central 9A/19A STR for donor 1034. B. Biased CO transmission. Transmission differences between the alleles of reciprocal COs estimated by the log rate ratio of the different recombinant haplotypes, calculated as $\log [(\mathrm{nRI} /$ totalRI)/(nRII/totalRII)]; where the denominator is the total number of normalized $\mathrm{CO}$ surveyed per reciprocal. The horizontal line at $\log \mathrm{R} R=0$ denotes the expected equal transmission of alleles between the reciprocal recombinant haplotypes. Asterisks denote a significant overtransmission $(\log R R>0)$ or under-transmission $(\operatorname{logRR}<0)$ based on the standardized Pearson residual. Three asterisks denote the strongest biased transmission $(p<0.001)$, two and one asterisk represent a $p$-value of $<0.01$ and $p<0.05$, respectively. C. NCOs overlap with CO frequencies. Shown are NCO frequencies (Poisson corrected and normalized between reciprocals) as red and blue lines compared to $\mathrm{CO}$ frequencies as grey shaded areas 
bioRxiv preprint doi: https://doi.org/10.1101/431841; this version posted October 3, 2018. The copyright holder for this preprint (which was not certified by peer review) is the author/funder, who has granted bioRxiv a license to display the preprint in perpetuity. It is made available under aCC-BY-NC-ND 4.0 International license.

950 from panel A, and the estimated NCO center averaged over Ho or Ht group as a black dashed line. D and E.

951 Observed NCOs for both reciprocals. Individual NCOs showing the converted alleles. The possible conversion tract length is denoted as a fine horizontal grey line between informative SNPs (shown on top of the panel). The mean conversion tract length is 625 bp and 1,354 bp for donor 1034 of donor 1227, respectively. Most NCO are single conversions involving only one SNP; however, co-conversions (tracts with more than one converted allele) and complex conversions (conversion tracts with a mixture of converted and original parental alleles) also a re observed.

957

958 

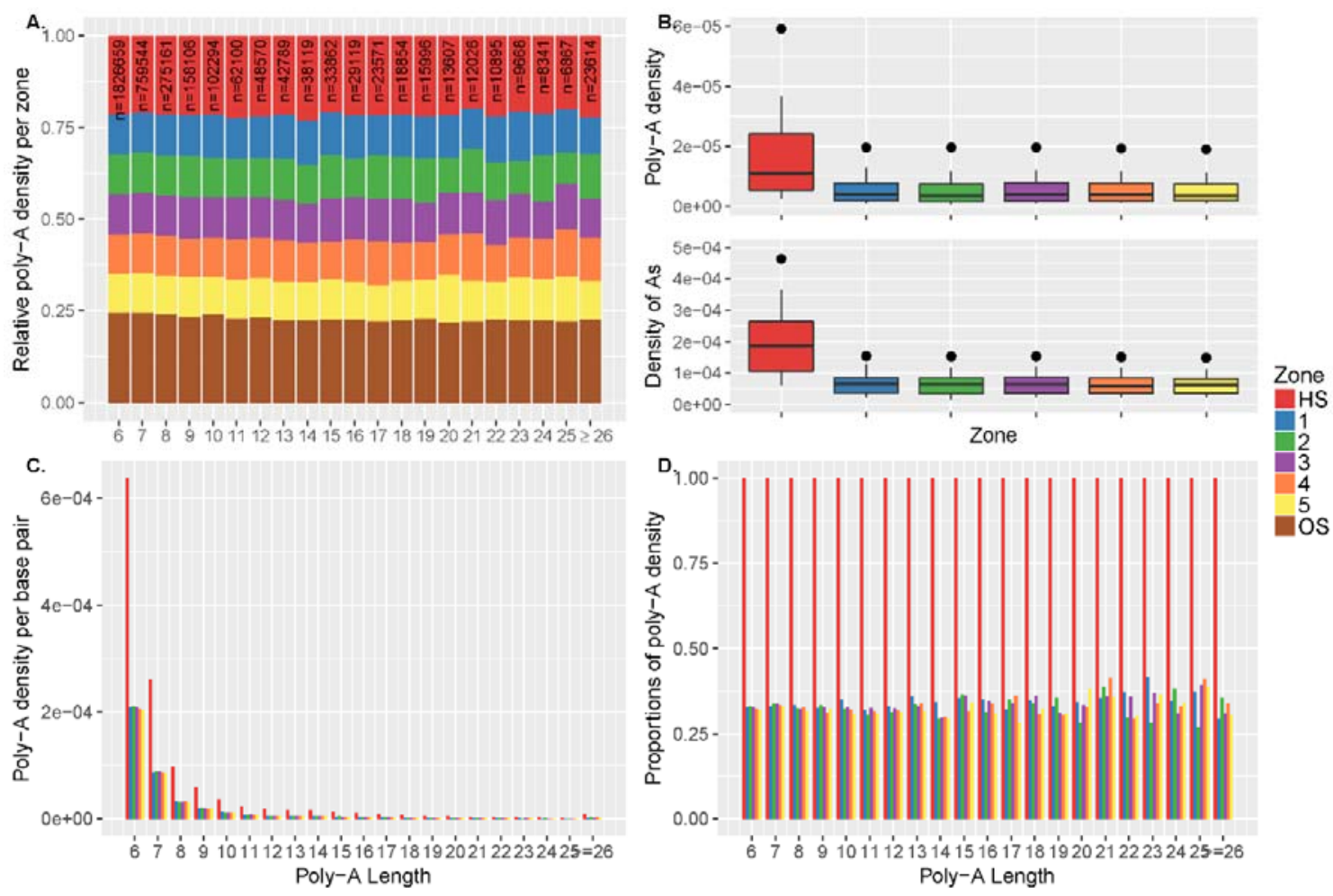

Figure 4. Poly-A enrichment at recombination hotspots. A. The poly-A density is the number of poly-As divided by the zone length. For each poly-A tract length $(6$ to $\geq 26 \mathrm{As})$, the densities were re-normalized $[0,1]$ by the sum of all densities. We extracted 3.5 million poly-As from the reference genome (GRCh37/hg19) that fall either within hotspots (HS; red), within flanking regions ( 5 sliding windows left and right of the hotspot, each 1 $\mathrm{kb}$ in length; $1-5$ ), or outside hotspot neighborhoods (OS; brown). Hotspots were defined as $\pm 500 \mathrm{bp}$ from the DSB coordinates of PRDM9A carriers identified by (Pratto et al., 2014), leading to an average hotspot length of $\sim 2 \mathrm{~kb}$. The subsequent zones were chosen as $1 \mathrm{~kb}$ segments upstream and downstream from the boundaries of the hotspot ( $2 \mathrm{~kb}$ in total per zone). Note that repeats with at least $26 \mathrm{As}$ are pooled into one class and outside regions (OS) are displayed only in panel A. B. Top panel: The poly-A density is the number of poly-As in a zone divided by the length of this zone in base pairs. We calculated the poly-A densities for each zone; total number of considered poly-As, $n=284,302$. Bottom panel: The densities of As per zone are calculated by dividing the number of As (length of the poly-A times its frequency) by the length of the zone in base pairs. The enrichment of poly-As within the hotspot compared to the flanking regions is approximately 3-fold for the poly-A densities and for the densities of As (in terms of mean and median). A Kruskal-Wallis test comparing all poly-As in hotspots vs. all flanking regions leads to highly significant results $(p<1 e-3$ and $p<1 e-5$ for poly-A density or density of As, respectively). C. The poly-A densities per base pair are shown stratified with respect to the length of the poly-A tract. D. The densities in the flanking regions are displayed as fractions relative to the densities within hotspots to better distinguish the enrich ment for longer poly-T tracts. 
bioRxiv preprint doi: https://doi.org/10.1101/431841; this version posted October 3, 2018. The copyright holder for this preprint (which was not certified by peer review) is the author/funder, who has granted bioRxiv a license to display the preprint in perpetuity. It is made available under aCC-BY-NC-ND 4.0 International license.

982

983

984

985

986

987

988

989

990

991

992

993

994

995

996

997

\section{B. Nuclease cleavage}

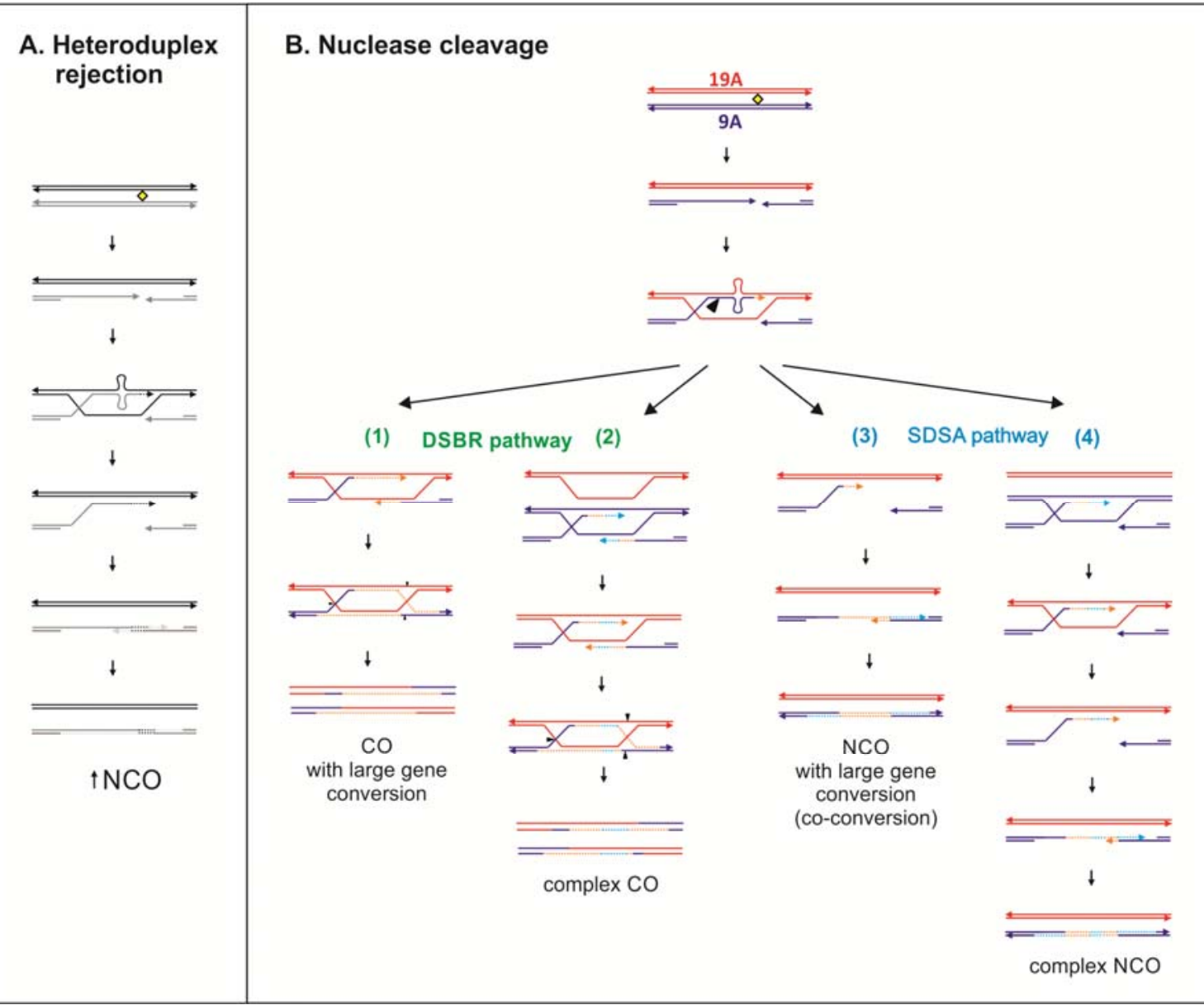

Figure 5. DSB repair of central 9A/19A repeat. A. The 9A/19A asymmetry can destabilize strand invasion leading to subsequent heteroduplex rejection resulting in more NCOs via the synthesis dependent strand annealing (SDSA) pathway. B. The formation of a $10 \mathrm{bp}$ heteroduplex activates the MMR/LLR system which likely removes the heterology by nuclease cleavage creating a large double-strand gap. Double-strand break repair (DSBR) forms COs or NCOs with large conversion tracts (1). Note that DSBR can also result in NCOs depending on the double Holliday cleavage sites (not indicated in the figure). Orange dashed lines represents the newly synthesized DNA. In case of sister-strand invasion (blue dashed lines), complex conversion tracts are formed (2). If strand displacement happens after the MMR endonucleolytic digestion past the asymmetry, NCOs with large conversion tracts (co-conversions) are formed (3), or alternatively complex conversions retaining the $9 \mathrm{~A}$ allele via inter-sister repair or possibly by LLR (not indicated) (4). 